\title{
New Goods and Asset Prices
}

\author{
Paul Scanlon* \\ Trinity College, Dublin
}

February 16, 2008

\begin{abstract}
I propose an extension to the consumption capital asset pricing model to incorporate the introduction of new goods over time and states of nature. In the model, consumers have a love of variety, and consumption consists of different components-product groups and brands. Expected growth in product groups increases expected future marginal utility, raising the incentive to save - thereby reducing the risk-free rate of interest. Meanwhile, variations in brand and quality growth over the business cycle make marginal utility more volatile and countercyclical—-thereby raising the expected equity premium.
\end{abstract}

*This is a revised version of part of my doctoral dissertation at the University of California, Berkeley. I thank my advisors, David Romer and Chad Jones, for helpful comments on an earlier version. Email: scanlop@tcd. ie 


\section{Introduction}

While the assumption of a single agent has received a lot of attention in the asset pricing literature, the assumption of a single good is largely overlooked. On the face of it, this is surprising: by affecting consumers' expected marginal utility, expected changes in product variety should affect their valuation of future payoffs - and therefore asset prices. Moreover, new goods affect marginal utility in different ways; the release of a new drug, for instance, has a different effect on marginal utility to the release of a new brand of wine. To address these issues, this paper proposes an extension to the consumption capital asset pricing model (CCAPM) to incorporate changes in product variety over time and states of nature.

In the CCAPM, the covariance of returns with marginal utility determines expected risk premia, while the risk-free rate is related to expected marginal utility growth. Because the standard model implicitly treats all goods — such as cars and wine-as perfect substitutes, variations in aggregate consumption fully determine variations in marginal utility. And essentially this is the source of the equity premium puzzle: consumption growth is very smooth. For this reason, there is little risk to holding equity, so only a high level of risk aversion can justify the realized equity premium. Closely related to this is the risk-free rate puzzle: given higher expected consumption of the same good in the future, coupled with diminishing marginal utility to that good, why do consumers still save, thereby keeping the risk-free rate so low? Clearly the one-good assumption is intimately related to both the stability of marginal utility growth and the expected decline in marginal utility over time-the very sources of the puzzles in the standard CCAPM.

Instead of consuming "more of the same," consumers in my setting consume an increasing variety of goods. By variety, I mean distinct product groups — such as cars-and relatively similar brands within each group — such as Volvos and Fords. Importantly, the number of groups and brands, together with the quality of each brand varies over time and states of nature. Consumers have a love of variety and diversify wealth over time, states of nature, financial assets, and all existing goods. Throughout, I maintain the basic framework of expected, time-separable, power utility, with complete, frictionless markets. 
Because consumers now care about what they consume, both the real consumption flow and product variety determine marginal utility. As a result, changes in variety result in different "states of the world," with states described by both the level of consumption and the variety of goods available. Here, new types of goods — such as computers-come on stream over time, while firms release better and more preferred brands in booms. Ultimately, this slows the decline in marginal utility over time and, by making marginal utility more volatile, it increases economy-wide undiversifiable consumption risk. Because financial assets are the means of transferring consumption across time and states of nature - to smooth (discounted) expected marginal utility — these dynamics affect asset prices.

To see the idea, consider the "tree economy" setting of Lucas (1978), where trees bear fruit—say, oranges - randomly, and consumers smooth marginal utility over time and states of nature. Faced with orange growth over time, consumption-smoothing consumers desire to borrow, thus driving up the risk-free rate. By contrast, in my setting, the future portends not only more oranges, but also fruit of a different nature; looking ahead, trees also bear apples, grapes, lemons, kiwis, pears, and so on. By increasing the demand for future consumption, this increases savings and lowers returns-in particular, the risk-free rate.

Now turning to the equity premium, in Lucas's setting, the covariance of marginal utility with the number of oranges falling from a tree determines the price of the tree. Since trees bearing more oranges when they are already plentiful provide poor consumption insurance, they command a risk premium. But in my setting, trees not only bear a greater number, but also a greater variety of oranges in a boom; now there are Florida oranges, California oranges, sweet ones, tender ones, organic ones, and so on. Because the consumption of a given number of oranges now provides more utility, consumer surplus or "real income" is relatively higher. As a result, consumption services now covary more with equity returns—-so equities command a higher risk premium.

Although variety growth over time is self-evident, is variety growth procyclical? Significantly, a number of theoretical models make this prediction. Leading examples in this literature include Shleifer (1986), who describes the business cycle in terms of "implementation cycles," whereby firms introduce new products at the same time; Schmookler (1966), who maintains that firms innovate in 
booms to avail of a greater market size; and, most famously, Schumpeter (1939), who depicts the business cycle in terms of "waves of creative destruction." More recently, several papers have reemphasized the role of firm entry and expanding product variety as a transmission mechanism over the business cycle (see, e.g., Jaimovich, 2004; Jovanovic, 1997; Bilbiie, Ghironi, and Melitz, 2007; and Corsetti and Bergin, 2005, among others). In these models, procyclical profits induce firm entry, thereby raising variety growth. Consistent with these predictions, procyclical variety growth is a feature of the data (see, e.g., Broda and Weinstein, 2007; Axerloglou, 2003; Divinney, 1990; and Yorukoglu, 2000, among others). For example, Broda and Weinstein (2007) find that "net product creation is strongly procyclical"; while Bilbiie et al. report that "disproportionately more varieties are introduced during US expansions." And discussing Tobin's Q theory, Cochrane (2008) points out that "the formation of new firms responds to market prices as much as does investment by old firms." Especially relevant here, this is a direct channel relating stock prices to variety growth. Yet, so far, no one has studied the asset pricing implications of trends and fluctuations in variety; therefore, this paper marks a first attempt to do so. ${ }^{1}$

I proceed as follows. After describing the model in Section 1, I discuss the asset pricing implications of variety growth in Section 2. In contrast to the standard CCAPM, the asset pricing kernel now depends on the variety of goods consumed. According to the model, group growth raises marginal utility, while brand and quality growth reduce it; intuitively, group growth creates more "needs," while brand and quality growth act to satiate those needs. Having presented the model, I then explore its implications for the two main asset pricing anomalies- the risk-free rate and equity premium puzzles - in Section 3. Rather than pricing only flow consumption risk, the expected equity premium now contains three new risk premia, all compensating for composition risk. Meanwhile, the risk-free

\footnotetext{
${ }^{1}$ Some recent contributions analyze the CCAPM in a multi-good framework. However, these contributions investigate variations in consumption over a fixed product space, so are qualitatively different to the setting here. For example, Piazzesi, Schneider, and Tuzel (2007) incorporate a consumption bundle of non-housing consumption and housing services into the CCAPM. They show that cyclical variations in these components can raise the expected equity premium, while long-run trends and volatility in the housing share raise precautionary savings and reduce the risk-free rate. Parker, Yogo and Ait-Sahalia (2004) examine how the consumption of luxury goods covaries with equity returns over the business cycle. Similarly, Pakoš (2004) and Yogo (2006) analyze the nondurable and durable consumption components of consumption and show how their interaction can increase consumption risk. Chetty and Szeidl (2007) stress the role of consumption commitments, which increase the variability of discretionary consumption. Finally, the classic contributions of Merton (1973) and Breeden (1979) consider variation in consumption opportunities, but in relation to changes in the relative prices of - again — a fixed number of goods.
} 
rate now depends on trends in variety and precautionary savings relating to composition risk.

Following the theory, Section 4 surveys some empirical work on high and low frequency variations of variety growth and the attendant welfare gains. Examining the sales of luxury goods over the business cycle enables me to determine the net effect of cyclical variety growth on marginal utility. Using these estimates, I approximate-albeit roughly—cyclical variation in variety growth and the associated welfare gains over the business cycle. Together with data on equity returns, I then estimate the expected equity premium. To ascertain the expected risk-free rate, I use long-run trends in labor supply. Because marginal utility growth determines long-run trends in labor supply, trends in labor supply enable me to determine the net effect of variety growth on the long-run trend in marginal utility. Exploiting this relationship, I simplify the expression for the expected risk-free rate. Compared to the standard CCAPM, the expected equity premium is higher, and the risk-free rate is lower for reasonable parameter values. Finally, Section 5 concludes.

\section{The Model}

There is a single representative consumer. Preferences are defined over a continuum of existing and potential consumption goods, including leisure. There is latent demand for all non-existent goods, and no good is essential. Consumption consists of different components, with the partition containing every existing and potential good. There are two margins of differentiation: product groups and brands. Product groups represent broad categories of goods without close substitutes and for which demand is relatively inelastic; for example, new medicines/treatments, cars, joint replacement, microwave ovens, VCRs, printers, laptops, lasik surgery, tvs, air-conditioning, cell phones, and so on. New goods on this margin represent "breakthrough" innovations. To keep things simple, there is a common elasticity of substitution between all groups. Given these goods are imperfect substitutes, the elasticity of substitution between them is less than one.

On the other hand, brands constitute different varieties or characteristics of goods within a given group - in terms of attributes like function, style, flavor, size, color, location of store, and so on. Since brands are relatively good substitutes, demand on this margin is elastic, and the elasticity of 
substitution between brands exceeds one. As with groups, there is a common elasticity of substitution between brands in a group. New goods on this margin represent incremental innovations.

Consumers exhibit a love of variety for groups and brands. For groups, one can explain this by the welfare improvement associated with large innovations: new groups cater to large unmet needs. Broadly, one can explain a love of variety for brands in two ways. First, with diminishing marginal utility to each good, there is a welfare gain to smoothing consumption over more goods. Faced with a variety of yoghurts, for example, the consumer might prefer to consume a little of each flavor; this is the Dixit-Stiglitz (1977) setup. Second, more variety permits consumers to attain their ideal brand or bundle of characteristics; this is the Lancaster (1979) formulation. ${ }^{2}$ Either way, welfare of the representative consumer rises with more variety; but, mostly for simplicity, I use the more tractable Dixit-Stiglitz formulation.

In addition to new brands, there is also vertical—i.e., quality enhancing-differentiation in each group, whereby the quality of each brand rises over time. In the case of yoghurts, for example, the addition of better flavoring to all existing yoghurts would constitute a quality increase. For this reason, welfare can increase without any change in the actual number of goods. Finally, all existing goods have a price of one, while non-existent goods have infinite prices.

\subsection{Consumer Preferences}

There is a continuum of differentiated product groups indexed along the infinite interval $[0, \infty)$. At any time $t$, there is only a measure $n_{t}<\infty$ of groups available for purchase. ${ }^{3}$ Associated with each group is a continuum of brands also indexed on $[0, \infty)$. At time $t$, there is a measure $m_{t}<\infty$ of brands available in each group, all of quality $A_{t} \in(0, \infty) .{ }^{4}$ The distributions of $m_{t}, n_{t}$, and $A_{t}$ are given exogenously: gross returns and the growth rates of wages, brands, groups, and quality are all random variables that are jointly normal and homoskedastic; i.e., $\frac{m_{t+1}}{m_{t}} \sim N\left(g_{m}, \sigma_{m}^{2}\right), \frac{A_{t+1}}{A_{t}} \sim$

\footnotetext{
${ }^{2}$ If consumers derive utility simply from the novelty of a new good, this would constitute another rationale for love of variety.

${ }^{3}$ Technically, this is the Lebesque measure of the Borel-measurable set, $\left[0, m_{t}\right]$.

${ }^{4}$ For convenience, I ignore indivisibilities and the non-integral nature of the variables $n$ and $m$, and from now on refer to them loosely as numbers. More generally, it is convenient to simply consider $m$ and $n$ as continuous indices of brand and group variety.
} 
$N\left(g_{A}, \sigma_{A}^{2}\right)$, and $\frac{n_{t+1}}{n_{t}} \sim N\left(g_{n}, \sigma_{n}^{2}\right)$. Groups are indexed by $j \in\left[0, n_{t}\right]$ and brands by $i \in\left[0, m_{t}\right]$. Therefore, $c_{j i t} \geq 0$ denotes the consumption service flow from brand $i$ in group $j$ at time $t$, while $c_{j t}$ denotes the service flow from group $j$ at time $t$. Period utility is a function of consumption services from product groups, $c_{j t}$, and labor, $l_{t} \in[0,1]$. Both individual groups and labor are separable in utility.

Dropping time subscripts, period utility, $U$, is of the form: $U \equiv$ $\left(c_{1}\left(c_{11}, c_{12}, \ldots, c_{1 m}, A\right), \ldots, c_{n}\left(c_{n 1}, c_{n 2}, \ldots, c_{n m}, A\right), l\right)$. This captures a fundamental desire for goods and services, rather than consumption per se. Now, consumption services from a group, $c_{j t}$, are given by the constant elasticity of substitution index:

$$
c_{j t} \equiv \mathfrak{m}_{t}^{v+1-\frac{1}{\alpha}}\left(\int_{0}^{m_{t}}\left(A_{t}^{\gamma} c_{j i t}\right)^{\alpha} d i\right)^{\frac{1}{\alpha}},
$$

where $c_{j i t} \geq 0, \alpha \in(0,1)$, and $\mathfrak{m}_{t}>0$ is the measure of brands actually consumed. A rise in $A_{t}$ increases the utility derived from the consumption of each brand, and $\gamma>0$ mediates the taste for quality. For clarity, I set the upper integral limit to $m_{t}$ and not to infinity, but keep in mind that utility is defined over an continuum of goods. ${ }^{5}$ Since there is a continuum of brands, the elasticity of substitution between brands within a group is $\frac{1}{1-\alpha} \in(1, \infty)$.

Following Benassy (1996), the parameter, $v \in(0, \infty)$, mediates the taste for brand variety. This governs the elasticity of the marginal utility of consumption with respect to the measure of brands consumed. Precisely, it disentangles the distinct concepts of love of variety and the degree of substitutability between goods (which is also the elasticity of demand for each brand). To see why, suppose consumption expenditure on a group is $C_{t}$. Given symmetry and concavity, all available goods are consumed in equal quantities, so $\mathfrak{m}_{t}=m_{t}$, and $c_{j t}=m_{t}^{v+1-\frac{1}{\alpha}} m_{t}^{\left(\frac{1}{\alpha}-1\right)} A_{t}^{\gamma} C_{t}=m_{t}^{v} A_{t}^{\gamma} C_{t}$. Clearly $v>0$ now mediates the marginal utility gain to more brands. As a result, this can handle situations where consumers might be highly responsive to price changes but still have a large taste for variety; or cases where consumers have little taste for variety, yet perceive goods as imperfect substitutes. ${ }^{6}$

\footnotetext{
${ }^{5}$ More explicitly, $c_{j t} \equiv \mathfrak{m}_{t}^{v+1-\frac{1}{\alpha}}\left(\int_{0}^{\infty}\left(A_{t}^{\gamma} c_{j i t}\right)^{\alpha} d i\right)^{\frac{1}{\alpha}}$, where $\mathfrak{m}_{t}^{v+1-\frac{1}{\alpha}}\left(\int_{m_{t}}^{\infty}\left(A_{t}^{\gamma} c_{j i t}\right)^{\alpha} d i\right)^{\frac{1}{\alpha}}=0$.

${ }^{6} \mathrm{By}$ comparison, the standard Dixit-Stiglitz function conflates the degree of love of variety with the elasticity of substitution (and elasticity of demand) and implies $v=\frac{1}{\alpha}-1>0$.
} 
Now define:

$$
u\left(c_{j t}\right)=\frac{\left(c_{j t}+\epsilon\right)^{1-\theta}}{1-\theta}
$$

where $\theta>1, \epsilon>0$, and $c_{j t} \gg \epsilon \approx 0$. For now, assume only a single group exists. Then the utility from the consumption services of a group, $c_{j t}$, is given by:

$$
u\left(c_{j t}\right)-u(0)=\frac{\left(c_{j t}+\epsilon\right)^{1-\theta}}{1-\theta}-\frac{\epsilon^{1-\theta}}{1-\theta} \geq 0 .
$$

The constant, $\epsilon$, is arbitrarily small and mediates the utility gain from consuming any positive quantity of the group. Since $\theta>1$, it ensures utility is well-defined defined when $c_{j t}=0$ and, in addition, that the utility flow from consuming a group is positive. Otherwise, it plays no role in the results. Since $\epsilon \approx 0$, even a small amount of consumption on a new group raises utility significantly; hence, there is a sizable welfare gain to distinct new innovations, irrespective of the quantity consumed. Subsequently, utility will increase as more of the group is consumed, but at a diminishing rate.

Period utility from the consumption services when $n_{t}$ groups exist is:

$$
\mathfrak{n}_{t}^{\phi} \int_{0}^{n_{t}} u\left(c_{j t}\right)-u(0) d j=\mathfrak{n}_{t}^{\phi} \int_{0}^{n_{t}} \frac{\left(c_{j t}+\epsilon\right)^{1-\theta}}{1-\theta}-\frac{\epsilon^{1-\theta}}{1-\theta} d j
$$

where $\phi>-1$, and $\mathfrak{n}_{t}$ denotes the measure of groups actually consumed. ${ }^{7}$ The constant, $\frac{1}{\theta}<1$, is the elasticity of intertemporal substitution of consumption services from each group across time. ${ }^{8}$ Because groups are separable in utility, $\frac{1}{\theta}$ is also the elasticity of substitution between groups. As a result, consumption services in different periods and consumption services of different groups are equally substitutable. By assumption, $\theta>1$, and most empirical evidence indicates that the intertemporal elasticity of substitution is also below one, so this is a reasonable simplification.

${ }^{7}$ As with brands, more explicitly we have:

$$
\mathfrak{n}_{t}^{\phi} \int_{0}^{n_{t}} u\left(c_{j t}\right)-u(0) d j=\mathfrak{n}_{t}^{\phi}\left(\int_{0}^{n_{t}} u\left(c_{j t}\right)-u(0) d j+\int_{n_{t}}^{\infty} u(0)-u(0) d j\right)
$$

${ }^{8}$ Strictly speaking, this is an approximation that only is true asymptotically. The elasticity of intertemporal substitution is $\frac{c_{j t}+\epsilon}{\theta c_{j t}}$. But since $\epsilon \approx 0, \frac{c_{j t}+\epsilon}{\theta c_{j t}} \approx \frac{1}{\theta}$ for all consumption levels. 
Here, $\phi$ plays a role similar to that of $v$ in the discussion of brands: it disentangles the degree of love of variety for groups from the elasticity of substitution between groups. To see why, let $\bar{c}_{j t}$ denote the equilibrium level of consumption services in each group. Then, if $\mathfrak{n}_{t}$ groups are consumed in equilibrium, the optimal level of utility is given by: $\mathfrak{n}_{t}^{\phi}\left(\mathfrak{n}_{t}\left(u\left(\bar{c}_{j t}\right)-u(0)\right)\right)=\mathfrak{n}_{t}^{\phi+1}\left(u\left(\bar{c}_{j t}\right)-u(0)\right)$. Therefore, holding the level of consumption services in each group constant, $\phi>-1$ mediates how utility varies as the number of groups rises. And since $\phi>-1, \mathfrak{n}_{t}^{\phi+1}$ is increasing in $\mathfrak{n}_{t}$, so there is always a gain to increasing the number of groups consumed; hence $\mathfrak{n}_{t}=n_{t}$ in equilibrium.

Keeping $c_{j t}$ on other groups fixed, if $-1<\phi<0$, there is decreasing marginal utility to the number of groups consumed. If $\phi=0$, groups are independent and hence additively separable in utility. Finally, if $\phi>0$, there is increasing marginal utility to the number of groups; new goods supplement the usefulness of existing ones. To give an example of this, suppose there are only two groups: food and recreation. Then a third group—say, cars—is introduced. Keeping expenditure on all groups fixed, the introduction of cars now has two effects. Since consumers can now travel to nice restaurants, it raises the marginal utility of food; and since consumers can now easily travel to airports for vacations, it raises the marginal utility of recreation. This way, a new group can have a positive effect on the marginal utility of other groups.

\subsubsection{Specification of Lifetime Utility}

The consumer has a horizon of $T$ periods and takes the distributions of $m_{t}, A_{t}$, and $n_{t}$ as given. Expected lifetime utility is given by:

$$
\mathbb{U} \equiv \mathbb{E}_{0} \sum_{t=0}^{T} \beta^{t}\left(\mathfrak{n}_{t}^{\phi} \int_{0}^{n_{t}} u\left(c_{j t}\right)-u(0) d j-\chi \frac{l_{t}^{1+\psi}}{1+\psi}\right),
$$

where $\mathbb{E}_{0}\{\}$ is an expectations operator, conditional on information at time $t=0$. The subjective rate of time preference is $\rho>0$, and $\beta \equiv \frac{1}{1+\rho}<1$. The Frisch elasticity of labor supply is $\frac{1}{\psi}>0$, and $\chi$ mediates the preference for leisure. 


\subsection{The Solution to the Intratemporal Problem}

First I solve the intratemporal problem under certainty in period $t$. Given that utility is both timeseparable and separable in consumption and leisure, I find the optimal allocation of goods each period, subject to some given level of consumption expenditure, $C_{t}$. By symmetry and the strict concavity of utility, the consumer will spend $\frac{C_{t}}{n_{t}}$ on each existing group. Applying the same reasoning to brands, and noting prices of unity for each existing good, the quantities demanded of each existing good are: $c_{j i t}=\frac{C_{t}}{m_{t} n_{t}}>0, \quad \forall j \in\left[0, n_{t}\right], \quad \forall i \in\left[0, m_{t}\right]$. Plugging these demands into (1) implies that the optimal level of consumption services from group $j$ at time $t$ is

$$
\sup _{\left\{c_{j i t} \geq 0\right\}}\left\{c_{j t}: \int_{0}^{m_{t}} c_{j i t} d i=\frac{C_{t}}{n_{t}}\right\}=m_{t}^{v} A_{t}^{\gamma} \frac{C_{t}}{n_{t}} .
$$

Substituting the optimal $c_{j t}$ into Eq. (2) gives the period indirect utility function for consumption:

$$
V\left(C_{t}, m_{t}, n_{t}, A_{t}\right)=\frac{n_{t}^{\phi+1}\left(m_{t}^{v} A_{t}^{\gamma} \frac{C_{t}}{n_{t}}+\epsilon\right)^{1-\theta}}{1-\theta}+\frac{n_{t}^{\phi+1}}{(\theta-1) \epsilon^{\theta-1}} .
$$

For convenience, define $\zeta=\phi+\theta>0$, and noting that $\frac{m_{t}^{v} A_{t}^{\gamma} C_{t}}{n_{t}} \gg \epsilon \approx 0$, I approximate to get:

$$
V\left(C_{t}, n_{t}, m_{t}, A_{t}\right) \approx \frac{n_{t}^{\zeta} m_{t}^{v(1-\theta)} A_{t}^{\gamma(1-\theta)} C_{t}^{1-\theta}}{1-\theta}+\frac{n_{t}^{\phi+1}}{(\theta-1) \epsilon^{\theta-1}}
$$

Finally, the reduced form expected lifetime utility is:

$$
\mathbb{U} \equiv \mathbb{E}_{0} \sum_{t=0}^{T} \beta^{t}\left(\frac{n_{t}^{\zeta} m_{t}^{v(1-\theta)} A_{t}^{\gamma(1-\theta)} C_{t}^{1-\theta}}{1-\theta}+\frac{n_{t}^{\phi+1}}{(\theta-1) \epsilon^{\theta-1}}-\chi \frac{l_{t}^{1+\psi}}{1+\psi}\right)
$$

\subsection{Discussion of Intertemporal Problem}

Two important points follow from Eq. (4). First, in contrast to the standard model—where $V\left(C_{t}\right)=$ $\frac{C_{t}{ }^{1-\theta}}{1-\theta}$-the indirect utility function for consumption now depends on the variety of goods consumed. ${ }^{9}$ For this reason, when $m_{t}, n_{t}$, and $A_{t}$ vary over time and states of nature, $V\left(C_{t}\right)$ and hence

\footnotetext{
${ }^{9}$ In this setting, standard tests of consumer optimality are technically joint tests of consumer optimality and no love of variety. These tests uniformly reject the standard one-good model (see, e.g., Hansen and Singleton, 1984;
} 
$V^{\prime}\left(C_{t}\right)$ become time and state-dependent. As a result, the traditional interpretation of the permanent income hypothesis - that is, smoothing real consumption expenditure over time and states-is not necessarily optimal in this setting. Moreover, by setting $n_{t}=m_{t}=A_{t}=1$, notice that the resulting utility function represents the same preferences as in the standard one-good model. That is, the standard model is a special case of a multi-good setup, where the level of variety is constant. Another interpretation is that the standard case assumes no love of variety, and all goods—such as cars and new medical treatments—are perfect substitutes in the eyes of consumers.

Second, the intertemporal elasticity of substitution for real consumption expenditure is $\frac{1}{\theta}$, which in this power utility setting is also the inverse of the coefficient of relative risk aversion, $\theta$. Although there may be sharp diminishing marginal utility to consumption expenditure at any given point in time, marginal utility does not necessarily fall this fast over time. Namely, growth in $n$ counters diminishing marginal utility. Indeed, when accompanied by a rise in $n$, a rise in consumption could be associated with a rise in marginal utility. Later on, this feature plays a key role in reconciling moderately high risk aversion and low intertemporal elasticity of substitution at any given point in time with apparently high intertemporal substitution over the long run. Finally, since $V^{\prime \prime \prime}>0$, precautionary savings will arise due to expected fluctuations in the values of the variables $C_{t}, A_{t}, m_{t}$, and $n_{t}$.

\subsection{The Effect of Variety on Marginal Utility}

From Eq. (4), marginal utility is:

$$
V^{\prime}\left(C_{t}\right)=\frac{n_{t}^{\zeta}}{m_{t}^{v(\theta-1)} A_{t}^{\gamma(\theta-1)} C_{t}^{\theta}} .
$$

Importantly, since $\theta>1$, we have: $\frac{\partial^{2} V}{\partial m_{t} \partial C_{t}}<0, \frac{\partial^{2} V}{\partial A_{t} \partial C_{t}}<0$, and $\frac{\partial^{2} V}{\partial n_{t} \partial C_{t}}>0$. Why is marginal utility decreasing in $m_{t}$ and $A_{t}$, but increasing in $n_{t}$ ? To see this, recall that the optimal value of $c_{j t}$ is:

Mankiw, Rotemberg, and Summers, 1986; and Grossman and Shiller, 1981). Moreover, the variety component of utility, $n_{t}^{\zeta} m_{t}^{v(1-\theta)} A_{t}^{\gamma(1-\theta)}$, which can be interpreted as a taste shock, is potentially correlated with consumption growth. This potential for taste shocks to invalidate tests of Euler equations was made forcefully by Garber and King (1983). 


$$
c_{j t}=m_{t}^{v} A_{t}^{\gamma} \frac{C_{t}}{n_{t}}
$$

Expressed this way, one can view $\frac{C_{t}}{n_{t}}, A_{t}^{\gamma}$ and $m_{t}^{v}$ as distinct substitutable inputs, all combining to produce consumption services, $c_{j t}$. Because these inputs enter in Cobb-Douglas form, the intratemporal elasticity of substitution between the inputs $m_{t}^{v}, \frac{C}{n}$, and $A_{t}^{\gamma}$ is unity.

Now, to simplify things, set $\epsilon=0$, so utility from $c_{j t}$ reduces to:

$$
u\left(c_{j t}\right)=\frac{n_{t}^{\phi}\left(m_{t}^{v} A_{t}^{\gamma} \frac{C_{t}}{n_{t}}\right)^{1-\theta}}{1-\theta} .
$$

The consumer has preferences defined over two margins: one, the consumer cares about composition; i.e., allocating inputs- $\frac{C_{t}}{n_{t}}, A_{t}^{\gamma}$, and $m_{t}^{v}$ - to yield consumption services from each group; and two, the consumer cares about the level of consumption services across time and groups; i.e., allocating the level of consumption services, $c_{j t}$, over groups and time. ${ }^{10}$ Given that $\theta>1$, the elasticity of substitution between brands $m_{t}^{v}$, quality, $A_{t}^{\gamma}$, and consumption per group, $\frac{C_{t}}{n_{t}}$, exceeds that of time and groups. So compared to consumption services in each period and group, $m_{t}^{v}, A_{t}^{\gamma}$, and $\frac{C_{t}}{n_{t}}$ are relatively good substitutes. As a result, consumers are more concerned about attaining similar levels of $c_{j t}$ across groups and time than with smoothing the level of each input in the consumption basket.

A rise in the number of groups, $n_{t}$, has two effects on marginal utility. Since consumers smooth expenditure, $C_{t}$, over groups, observe from Eq. (7) that a rise in $n_{t}$ reduces the consumption of each group, $\frac{C_{t}}{n_{t}}$. Because consumers strongly desire to smooth the level of consumption services across groups, this consumption "widening" raises the marginal utility of consumption of each group in period $t$. In addition, there is a direct effect due to $\phi$. Holding expenditure on all groups fixed, increasing the number of groups consumed affects the marginal utility of consumption of other groups.

By contrast, a rise in $m_{t}$ and $A_{t}$ leads to consumption "deepening," since this raises the level of consumption services from a given amount of expenditure on each existing group in a period. And since consumers desire to equate the level of $c_{j t}$ for all $j$ and $t$, they quickly become satiated as

\footnotetext{
${ }^{10}$ Implicitly the standard one-good model assumes the consumer only cares about levels and is risk-neutral over composition. But there is no a priori reason to believe this to be the case.
} 
consumption services rise in a given period. Rather than consuming more, consumers desire to shift real consumption resources to other periods. For this reason, a rise in $m_{t}$ or $A_{t}$ in a period reduces marginal utility that period. To summarize, we have the following propositions:

Proposition 1 : A rise in the number of brands, $m_{t}$, or the level of quality, $A_{t}$, in a period reduces the marginal utility of consumption in that period; i.e., $\frac{\partial^{2} V}{\partial m_{t} \partial C_{t}}<0$, and $\frac{\partial^{2} V}{\partial A_{t} \partial C_{t}}<0$.

Proposition 2 : A rise in the number of groups, $n_{t}$, in a period raises the marginal utility of consumption in that period; i.e., $\frac{\partial^{2} V}{\partial n_{t} \partial C_{t}}>0$.

\section{Asset Pricing and The Pricing Kernel}

In this section I turn to the asset pricing implications of the analysis. Denoting the asset price by $p_{t}$ and the payoff in period $t_{t+1}$ by $x_{t+1}$, the standard equilibrium relationship for holding an asset is:

$$
p_{t} V^{\prime}\left(C_{t}\right)=\beta \mathbb{E}_{t}\left[x_{t+1} V^{\prime}\left(C_{t+1}\right)\right],
$$

for $0<t<T$. Taking marginal utility growth as given, this optimality condition prices every asset in the economy.

Letting $M_{t+1} \equiv \frac{\beta V^{\prime}\left(C_{t+1}\right)}{V^{\prime}\left(C_{t}\right)}>0$, from Eq. (8) above, the fundamental asset pricing equation is: $p_{t}=$ $\mathbb{E}_{t}\left(M_{t+1} x_{t+1}\right)$. The random variable, $M_{t+1}$, mediates how future payoffs are valued, and assuming markets are complete, $M_{t+1}$ is the same for all consumers. The covariance of any return with $M_{t+1}$ represents the macroeconomic, undiversifiable risk of the asset and hence determines the asset's risk premium. Now taking unconditional expectations of (8) gives the asset price:

$$
p_{t}=\mathbb{E}\left[M_{t+1} x_{t+1}\right]=\mathbb{E} M_{t+1} \mathbb{E} x_{t+1}+\operatorname{Cov}\left(M_{t+1}, x_{t+1}\right) .
$$

And from Eq. (6) the asset pricing kernel $M_{t+1}$ is:

$$
M_{t+1}=\frac{\beta V^{\prime}\left(C_{t+1}\right)}{V^{\prime}\left(C_{t}\right)}=\beta\left(\frac{C_{t+1}}{C_{t}}\right)^{-\theta}\left(\frac{m_{t+1}}{m_{t}}\right)^{v(1-\theta)}\left(\frac{A_{t+1}}{A_{t}}\right)^{\gamma(1-\theta)}\left(\frac{n_{t+1}}{n_{t}}\right)^{\zeta}>0 .
$$




\subsection{Price of Risk-Free assets}

A risk-free asset has a certain payoff of unity in all states-i.e., $x_{t+1}=1$-and its return does not covary with the kernel. From Eq.(9), the equilibrium price of a risk-free bond is:

$$
p_{f t}=\beta \mathbb{E}\left(\frac{C_{t+1}}{C_{t}}\right)^{-\theta}\left(\frac{m_{t+1}}{m_{t}}\right)^{v(1-\theta)}\left(\frac{A_{t+1}}{A_{t}}\right)^{\gamma(1-\theta)}\left(\frac{n_{t+1}}{n_{t}}\right)^{\zeta}
$$

High expected marginal utility raises savings and, in turn, increases the demand for assets and hence the price of risk-free bonds. As already noted, higher trend growth in groups raises future marginal utility and increases the expected value of payoffs. By raising the incentive to save, this increases the asset price and lowers returns. In contrast, trend growth in each of brands, quality, and consumption lowers future marginal utility. This lowers savings and the demand for financial assets, inducing a lower price of risk-free bonds, $p_{t}$, and a corresponding rise in the risk-free rate. Taste parameters, $v, \gamma, \theta$, and $\zeta$ govern the magnitudes of these effects.

Covariances also affect the risk-free rate. For example, if consumers expect brand and quality growth to move together, then this interaction will make marginal utility more variable. This raises the precautionary demand for savings, leading to a higher asset price and a corresponding fall in the return. A higher discount factor, $\beta$, indicates greater patience and hence a greater weight on the future; this increases the demand for assets, thereby increasing the asset price. Finally, denoting the net risk-free rate by $r_{f_{t+1}}$, from Eq.(8) above, $\mathbb{E}\left[M_{t+1}\left(1+r_{f_{t+1}}\right)\right]=1 \Rightarrow 1+r_{f_{t+1}}=\frac{1}{\mathbb{E}\left(M_{t+1}\right)}$.

\subsection{Price of Risky Assets}

The covariance of $M_{t+1}$ with the payoff $x_{t+1}$ from the risky asset determines expected risk premia. Combining Eq.(9) with $\mathbb{E}\left(M_{t+1}\right)=\frac{1}{1+r_{f t+1}}$ yields:

$$
p_{t}=\frac{\mathbb{E}\left(x_{t+1}\right)}{1+r_{f_{t+1}}}+\operatorname{Cov}\left(\beta\left(\frac{C_{t+1}}{C_{t}}\right)^{-\theta}\left(\frac{m_{t+1}}{m_{t}}\right)^{v(1-\theta)}\left(\frac{A_{t+1}}{A_{t}}\right)^{\gamma(1-\theta)}\left(\frac{n_{t+1}}{n_{t}}\right)^{\zeta}, x_{t+1}\right) .
$$

The asset price is comprised of the expected payoff discounted at the risk-free rate together with a risk premium. Because $m, A$ and $n$ are aggregate, macroeconomic variables, random changes in these 
variables represent systematic composition risk. By analogy with Merton (1973), there are now risks to the consumption opportunity set. Provided there is a taste for variety, there is still a risk premium arising from composition risk even if consumption is stable.

Whether equilibrium prices rise or fall as a result of variety growth depends on covariances of variety growth with asset payoffs. Because group growth raises future marginal utility, positive covariance of returns with group growth increases the demand for the asset. In equilibrium, such a useful asset will command a higher price and hence a relatively lower expected return. Conversely, assets whose payoffs have positive covariance with consumption, brand, and quality growth destabilize marginal utility growth and provide poor consumption insurance. For bearing this risk, investors are compensated with a positive risk premium and a lower asset price.

\section{Asset Pricing Puzzles}

In this section I discuss the two main asset pricing anomalies: the risk-free rate and equity premium puzzles. First, I briefly review the optimality conditions from the benchmark, one-good CCAPM (i.e., where $n=m=A=1$ or, equivalently, when $v=\gamma=\zeta=0)$ and then present the conditions for the variety-adjusted model. Taking the United States as a benchmark, the risky asset refers to the market portfolio- - here, the S \& P index — and Treasury bills proxy for the risk-free asset. Aggregate consumption growth refers to the growth of nondurables and services consumption. Notationally, $\sigma_{x}$ denotes the standard deviation of the random variable $x, \rho_{x y}$ the correlation of random variables $x$ and $y$, and $\sigma_{x y}=\rho_{x, y} \sigma_{x} \sigma_{y}$ the covariance of $x$ and $y$. Finally, $\frac{z_{t+1}}{z_{t}}=1+\tilde{g}_{z}$, where $\tilde{g}_{z}$ is the net growth rate of $z$, and $\mathbb{E} \tilde{g}_{z}=g_{z}$.

\subsection{Equilibrium Returns in a One-Good World}

By setting $v=\gamma=\zeta=0$, the variety-adjusted kernel, Eq. (10), reduces to the standard one-good pricing kernel: $M_{t+1}=\beta \frac{V^{\prime}\left(C_{t+1}\right)}{V^{\prime}\left(C_{t}\right)}=\beta\left(\frac{C_{t+1}}{C_{t}}\right)^{-\theta}>0$. Now set $\frac{x_{t+1}}{p_{t}} \equiv 1+\tilde{r}_{t+1}$, where $\tilde{r}$ is the return on any asset. Substituting these relationships into Eq. (8), taking unconditional expectations, and 
dropping time subscripts gives the unconditional stochastic Euler equation:

$$
1=\beta \mathbb{E}\left[(1+\tilde{r})\left(1+\tilde{g}_{c}\right)^{-\theta}\right]
$$

To simplify this expression, I take a second order Taylor series approximation of $(1+\tilde{r})\left(1+\tilde{g}_{c}\right)^{-\theta}$ around $\tilde{r}=\tilde{g}_{c}=0$. After eliminating small terms, the equation for the expected risk-free rate reduces to:

$$
r_{f}=\rho+\theta g_{c}-\frac{1}{2} \theta(\theta+1) \sigma_{g_{c}}^{2}
$$

Then taking differences of the simplified Euler equations for both the risk-free rate and the market portfolio gives the unconditional expected equity premium:

$$
\mathbb{E}\left(\tilde{r}-r_{f}\right)=\theta \sigma_{r, g_{c}}=\theta \sigma_{r} \sigma_{g_{c}} \rho_{r, g_{c}} .
$$

Equation (12) is the asset allocation rule and relates to the smoothing of marginal utility over states of nature. By amplifying good and bad times, a higher covariance of market returns with consumption growth raises consumption risk, and hence the expected equity premium. The equity premium puzzle corresponds to the failure of Eq.(12) to hold. For example, in the United States from 1890 to 1979 , the left-hand side is around 6 percent, while $\sigma_{r, g_{c}} \approx .24$. Given that the quantity of risk, as conveyed by $\sigma_{r, g_{c}}$ is relatively low, the level of risk aversion must be high to justify the high realized equity premium; here we need $\theta=25$. Figure 1 shows the root of the puzzle-the smoothness of aggregate consumption growth relative to equity returns.

Equation (11) relates to savings and the smoothing of expected marginal utility over time. Given expected consumption growth over time, consumption smoothing predicts a relatively high marketclearing risk-free rate. According to Eq. (11), with observed consumption growth of 2 percent and $\theta=25, r_{f} \approx 23$ percent, but in reality $r_{f} \approx 1$. This inability of the standard one-good CCAPM to reconcile a steep consumption profile with a strong desire to smooth consumption is the risk-free rate puzzle. 


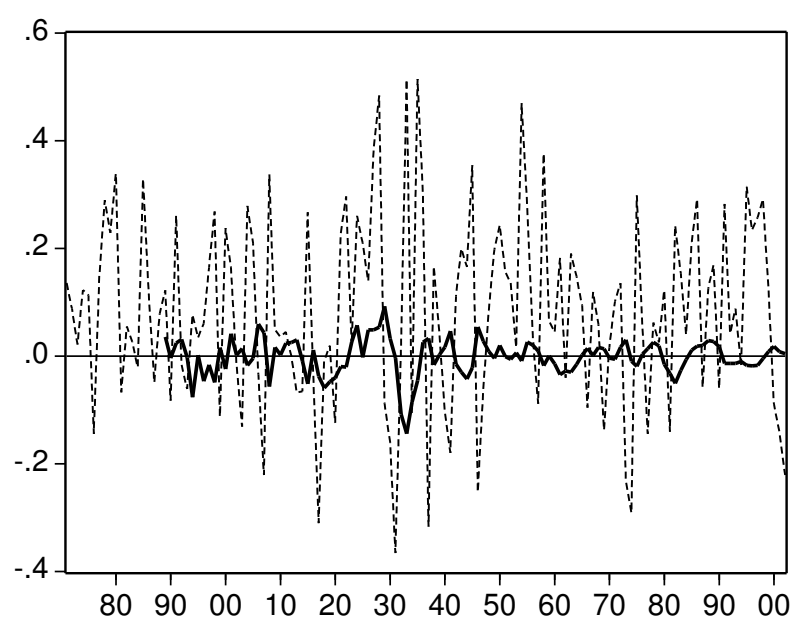

- Consumption Deviation From Trend Returns (S\&P)

Figure 1: Equity Returns and CyClical Components of Consumption Growth: United STATES, 1890-2002

SOURCE: RobERT SHILlER's WEBSITE.

Yet even allowing for generous values of $\rho=2$ percent, $g_{c}=2$ percent, and $\theta=2$, we have $r_{f} \approx \rho+\theta g_{c} \approx 6$ percent, which is about four times the actual rate. ${ }^{11}$ Although precautionary savings tend to depress the risk-free rate, they are small in this complete markets setup. Moreover, from Eq. (11), $\sigma_{r_{f}}^{2} \approx \theta^{2} \sigma_{g_{c}}^{2}$, so a high $\theta$ also predicts-counterfactually-high interest rate volatility across time and space. An unrealistically large negative discount factor is the only way to ensure equality of Eq. (11).

\subsection{Equilibrium Returns with New Goods}

I now show how the introduction of new goods alters expected returns. Substituting the varietyadjusted pricing kernel, Eq. (10), into the standard Euler equation and dropping time subscripts gives:

\footnotetext{
${ }^{11}$ Aside from the equity premium implications, actual empirical estimates of the intertemporal elasticity of substitution (IES) are low. For example, Campbell (2001) notes that "direct evidence on the elasticity of intertemporal substitution suggests that it is fairly low, certainly well below one [i.e., $\theta>1$ ]." Hall (1988) estimates the inverse of the IES to be ten, implying a risk-free rate of around twenty percent. Hall's (1988) value is fairly representative, and he suggests that the IES "may well be zero." Moreover, Cochrane (2008) asserts that "more recent macro literature has tended to side with Hall." Carroll and Summers (1989) claim that a value below .25 is standard. Studies based on micro data find estimates somewhat higher but not markedly so; for example, using micro data, Attanasio and Weber (1995) report estimates in the range $[.48, .67]$. For this reason, efforts to disentangle risk aversion and intertemporal substitution (i.e., Epstein and Zin (1989) and Kreps-Porteus (1978) preferences) are insufficient to generate a realistic risk-free rate.
} 


$$
1=\beta \mathbb{E}\left[(1+\tilde{r})\left(1+\tilde{g}_{c}\right)^{-\theta}\left(1+\tilde{g}_{m}\right)^{v(1-\theta)}\left(1+\tilde{g}_{A}\right)^{\gamma(1-\theta)}\left(1+\tilde{g}_{n}\right)^{\zeta}\right]
$$

As before, I take a second-order Taylor series expansion to approximate $(1+\tilde{r})\left(1+\tilde{g}_{c}\right)^{-\theta}(1+$ $\left.\tilde{g}_{m}\right)^{v(1-\theta)}\left(1+\tilde{g}_{A}\right)^{\gamma(1-\theta)}\left(1+\tilde{g}_{n}\right)^{\zeta}$ around the point $\tilde{r}=\tilde{g}_{c}=\tilde{g}_{m}=\tilde{g}_{n}=\tilde{g}_{A}=0$. After taking expectations, the expected risk-free rate reduces to:

$$
\begin{aligned}
r_{f}= & \rho+\theta g_{c}-v(1-\theta) g_{m}-\gamma(1-\theta) g_{A}-\zeta g_{n}-\frac{1}{2}\left(\theta(\theta+1) \sigma_{g_{c}}^{2}+v(1-\theta)(v(1-\theta)-1) \sigma_{g_{m}}^{2}\right. \\
& \left.+\gamma(1-\theta)(\gamma(1-\theta)-1) \sigma_{g_{A}}^{2}+\zeta(\zeta-1) \sigma_{g_{n}}^{2}\right)+v \theta(1-\theta) \sigma_{g_{m}} \sigma_{g_{c}} \rho_{g_{m}, g_{c}} \\
& +\gamma \theta(1-\theta) \sigma_{g_{A}} \sigma_{g_{c}} \rho_{g_{A}, g_{c}}+\theta \zeta \sigma_{g_{c}} \sigma_{g_{n}} \rho_{g_{c}, g_{n}}-v \gamma(1-\theta)^{2} \sigma_{g_{A}} \sigma_{g_{m}} \rho_{g_{A}, g_{m}} \\
& -v \zeta(1-\theta) \sigma_{g_{m}} \sigma_{g_{n}} \rho_{g_{m}, g_{n}}-\gamma \zeta(1-\theta) \sigma_{g_{A}} \sigma_{g_{n}} \rho_{g_{A}, g_{n}} .
\end{aligned}
$$

\subsection{Labor Trends and The Long-Run Trend in Marginal Utility Growth}

Before going on, I first simplify Eq. (13). According to the model, marginal utility growth determines both asset prices and long-run trends in labor supply. Then given labor/consumption separability, long-run trends in labor supply reflect the average growth of marginal utility over time. Denoting the real wage at time $t$ by $w_{t}$, from Eq.(5) the static neoclassical labor/leisure optimality condition is:

$$
w_{t} V^{\prime}\left(C_{t}\right)=\chi l_{t}^{\psi}
$$

that is, the real return to supplying an extra unit of labor is equal to the marginal disutility of labor. Taking growth rates of this condition and combining the result with the first order condition for consumption, $V^{\prime}\left(C_{t}\right)=\beta \mathbb{E}_{t}\left[\left(1+r_{f_{t+1}}\right) V^{\prime}\left(C_{t+1}\right)\right]$, simplifies the expression for the risk-free rate.

Over long periods of time, labor hours per capita are approximately constant (see, e.g., Francis and Ramey, 2006). To reconcile this observation with the model, the rate of increase of the wage, $w_{t}$, must equal the rate of decline in marginal utility, $V^{\prime}\left(C_{t}\right)$. Dropping time subscripts and taking growth rates and unconditional expectations of (14) gives: 


$$
\mathbb{E}\left(\frac{V^{\prime}(C)}{V^{\prime}(C)}\right)=-g_{w}
$$

that is, over the long run, marginal utility falls at the rate of consumption growth. Now substituting the expression for marginal utility, $V^{\prime}(C)=\frac{n^{\zeta} m^{v(1-\theta)} A^{\gamma(1-\theta)}}{C^{\theta}}$, into Eq. (15) and imposing the stylized fact that $g_{c}=g_{w}$ gives:

$$
\mathbb{E}\left(\frac{V^{\prime}(C)}{V^{\prime}(C)}\right)=-\theta g_{c}+\underbrace{v(1-\theta) g_{m}+\gamma(1-\theta) g_{A}+\zeta g_{n}}_{=(\theta-1) g_{c}>0}=-g_{c}
$$

In a one-good setting, marginal utility falls at rate $\theta g_{c}$. There, to reconcile stable labor hours with the standard CCAPM, we must impose logarithmic utility, $\theta=1$, which contradicts the empirical evidence on $\theta .^{12}$ In contrast, the variety model introduces the extra terms in brackets, which can rationalize stable labor hours. Significantly, these new terms imply that the rate of decline in marginal utility is lower relative to the one-good model.

Turning to magnitudes, since $g_{n}$ is most likely relatively low compared to $g_{m}$ and $g_{A}$, and all the other terms on the left- hand side of Eq. (16) are positive, the taste for groups, $\zeta$, must be relatively high. This is plausible: consumers surely place a greater valuation on a new product group than on a new brand. Hence, according to the model, growth in product groups is the main force maintaining a relatively stable labor supply over the long run.

\subsubsection{New Expression for the Risk-Free Rate with Variety Growth}

Notice now that the first terms in (16) also appear on the left of Eq. 13. Substituting (16) into (13) gives the equation for the expected risk-free rate:

\footnotetext{
${ }^{12}$ Significantly, the standard model fails to explain long-run trends in labor supply. Considering empirical estimates of the elasticity of intertemporal substitution, this model predicts labor supply falls sharply over time. To see why, recall the standard labor/leisure condition, $w_{t} V^{\prime}\left(C_{t}\right)=\chi l_{t}^{\psi}$, and note that $V^{\prime}\left(C_{t}\right)=\frac{1}{C_{t}^{\theta}}$ in the standard model. If $\theta=4$, then for stable hours, $\frac{w_{t}}{C_{t}^{4}}$ must be constant. Yet consumption per capita roughly doubled from 1960-2000, but wages increased at approximately the same rate.
} 


$$
\begin{aligned}
r_{f}= & \rho+g_{c}-\frac{1}{2}\left(\theta(\theta+1) \sigma_{g_{c}}^{2}+v(1-\theta)(v(1-\theta)-1) \sigma_{g_{m}}^{2}+\gamma(1-\theta)(\gamma(1-\theta)-1) \sigma_{g_{A}}^{2}\right. \\
& \left.+\zeta(\zeta-1) \sigma_{g_{n}}^{2}\right)+v \theta(1-\theta) \sigma_{g_{m}} \sigma_{g_{c}} \rho_{g_{m}, g_{c}}+\gamma \theta(1-\theta) \sigma_{g_{A}} \sigma_{g_{c}} \rho_{g_{A}, g_{c}}+\theta \zeta \sigma_{g_{c}} \sigma_{g_{n}} \rho_{g_{c}, g_{n}} \\
& -v \gamma(1-\theta)^{2} \sigma_{g_{A}} \sigma_{g_{m}} \rho_{g_{A}, g_{m}}-v \zeta(1-\theta) \sigma_{g_{m}} \sigma_{g_{n}} \rho_{g_{m}, g_{n}}-\gamma \zeta(1-\theta) \sigma_{g_{A}} \sigma_{g_{n}} \rho_{g_{A}, g_{n}} .
\end{aligned}
$$

Several points are worth noting. As in the standard model, the risk-free rate is constant. But in contrast to the standard CCAPM-where $r_{f}=\rho+\theta g_{c}-\frac{1}{2} \theta(\theta+1) \sigma_{g_{c}}^{2}$-the coefficient on expected consumption growth is unity, not $\theta$. In a deterministic setting without precautionary terms, the riskfree rate is now lower.

To see why, note that trend brand and quality growth act to reduce the price of future consumption services. This has the usual income and substitution effects, and given $\theta>1$, the income effect dominates, thereby reducing consumption growth. Because predictable group growth entails the spreading of services more thinly, this raises expected marginal utility. In turn, this raises savings and increases consumption growth. However, the labor evidence shows that variety growth raises optimal consumption growth relative to the standard one-good model. As a result, the effect of group growth ultimately causes savings to rise and the risk-free rate to fall.

Over the long run, the economy behaves as if the intertemporal elasticity of substitution is unity. Yet because empirical evidence suggests the degree of intertemporal substitution (IES) is low, the coefficient on the interest rate, $\frac{1}{\theta}$, will be small in standard regressions of consumption growth on interest rates. The true underlying short-run equation is still Eq. (13), so $\frac{\partial g_{c}}{\partial r_{f}}=\frac{1}{\theta}$. Although consumers appear to have a high IES in the long-run, this reflects the effect of variety growth on savings rather than intertemporal substitution.

Since marginal utility is convex, the volatility of real consumption and variety growth raises precautionary savings, again reducing the risk-free rate. As for covariance terms, consumption, brand, and quality growth all have the same effect on marginal utility. Hence, positive covariance between them amplifies variations in marginal utility. This increases the need for precautionary savings, thereby lowering the risk-free rate. In contrast, since group and brand/quality growth have oppos- 
ing effects on marginal utility, positive covariance of these variables acts like a hedge. By reducing the need for precautionary savings, this raises the risk-free rate.

\subsubsection{Expected Risk Premium with Changing Variety}

Taking differences of the Euler equations for both the risk-free bond and the risky asset gives the unconditional expected equity premium:

$$
\mathbb{E}\left(r_{t}-r_{f_{t}}\right)=\theta \sigma_{r} \sigma_{g_{c}} \rho_{r, g_{c}}+v(\theta-1) \sigma_{r} \sigma_{g_{m}} \rho_{r, g_{m}}+\gamma(\theta-1) \sigma_{r} \sigma_{g_{A}} \rho_{r, g_{A}}-\zeta \sigma_{r} \sigma_{g_{n}} \rho_{r, g_{n}} .
$$

Fluctuations in variety growth imply that the expression for the equity premium reduces to a linear four factor model. Covariance of the factors with market returns represents risks to the level of consumption services and therefore command a risk adjustment. For this reason, even without any flow consumption risk, there is still a risk premium due to composition risk. The taste parameters, $v$, $\gamma, \zeta$, and the coefficient of relative risk aversion, $\theta$, govern the size of the risk adjustments. Because $C, A, m$ and $n$ are nonstationary variables, their covariance with returns generates an equity premium at long horizons.

Positive covariance of equity returns with quality and brand growth raise the expected equity premium. Because growth of these variables acts to satiate the consumer, their positive covariance with returns amplifies changes in marginal utility, making stocks a poor hedge. For bearing this risk, stocks command a higher expected equity premium. In contrast, since groups raise marginal utility, a positive covariance of returns with group growth increases the value accorded to payoffs. In turn, this reduces the expected equity premium.

Although there may be no variation in real consumption resources, there is potentially a lot of variation in consumption services due to fluctuations in $A, m$, and $n$. To see this, assume there is a single group. Noting prices of unity, total resources devoted to consumption in period $t$ are then given by: $C_{t}=\int_{0}^{m_{t}} c_{t} d i$. Therefore, in the one-good world, consumption services are given by $C_{t}$, and since $g_{c_{t}}$ is relatively smooth $\left(\sigma_{g_{c}} \approx 3\right.$ percent), there is little apparent consumption risk. By contrast, 
in the variety-adjusted model, consumption services are given by $m_{t}^{v} A_{t}^{\gamma} C_{t}$, which are potentially more volatile.

\section{Empirical Evidence and Calibration}

Having presented the basic theory, I now turn to empirical evidence of trends in variety over time and states of nature. To quantify expected returns in this multi-good setup, it is important to approximate trends and volatility of the key state variables $A, n$, and $m$, together with their covariance with each other and with equity returns. While lack of precise data forbids a rigorous empirical analysis, a number of empirical studies provide evidence on some of the variables of interest. After briefly reviewing this work, I present a calibration. Yet given data limitations, any calibration is invariably rough, with the sole objective of attaining ballpark estimates of the model's predicted returns.

\subsection{Long-Run Trends in Variety Growth}

Cox and Alm (1997) report significant trends in the level of variety over time. For example, from the early seventies to the late nineties, the number of bicycle types increased from 8 to 31 ; the number of running shoe styles increased from 5 to 285 ; and the number of milk types increased from 4 to 19. Primarily these trends represent an increase in brands and quality in my setup. These findings are supported by Ebert and Griffin (2006), who report that firms in the United States introduce more than 25,000 new household, grocery and drugstore items annually; for example, in 2001 the beverage industry alone launched 3,800 products. Likewise, Klenow (2003) documents that the number of products carried by an average supermarket rose from 10,425 in 1978 to 40,333 in 2000. Examining expenditure patterns, Broda and Weinstein (2007) find that new goods comprise about nine percent of annual consumption expenditure. According to them, "almost 80 percent of the products that existed in 2003 were not around in 1994; these new products comprised 64 percent of expenditures in 2003.” Reviewing empirical evidence on variety, Bilbiie, Ghironi, and Melitz (2007) report: “for US aggregate manufacturing, the value of new goods produced represents just under 10 percent of annual 
manufacturing output."

Another indicator of variety growth is trademark registration. As shown in Figure 2, there is a trend increase in the number of trademarks issued in the United States from 1871-2002. Yorukoglu (2000) estimates that the average growth of new trademarks between 1903-1997 has been around 4 percent. Moreover, to the extent that new firms introduce new goods, trends in firm growth should also reflect broad trends in variety growth. For example, according to Perloff (2003), from 1989 to 1996 firm entry to all sectors averaged about ten percent (of existing firms) a year. And Ebert et al. report that between 1989 and 1999, annual business startups numbered between 150, 000 and 190, 000 in the United States. Still another source of variety growth is imports. Broda and Weinstein (2006) point out that the United States imported 74,667 varieties in 1972, which rose to 259,215 in 2001.

Cox and Alm (1997) observe that some distinct goods—such as computers-were non-existent in seventies; this would constitute an increase in groups in my setup. Another prominent example of group growth is the introduction of new drugs and medical treatments. Klenow (2003) reports that medical expenditure rose from 6.7 percent of consumption in 1960 to 17.4 percent in 2000, citing new medical procedures and drugs as “a major source.” Bils and Klenow (2001a) provide evidence of a direct positive relationship between expenditure shares on a given sector and increases in product variety in that sector. Most importantly, they attribute large increases in expenditure shares in certain categories—-such as electrical goods - to pronounced changes in variety in these sectors over time.

\subsection{Short-Run Trends in Variety Growth}

Turning to high frequency trends, Broda and Weinstein (2007) find that "in a typical year, forty percent of household expenditures are in goods that were created in the last four years." In a related study, Bernard, Redding and Schott (2006) find evidence of significant product turnover: accounting for entry, overall product creation accounts for 46.6 percent of output over a five year period for manufacturing firms in the United States, while product destruction accounts for 44 percent. Citing these figures, Melitz, Ghironi and Bilbiie (2007) speculate that "annual contributions using a finer 


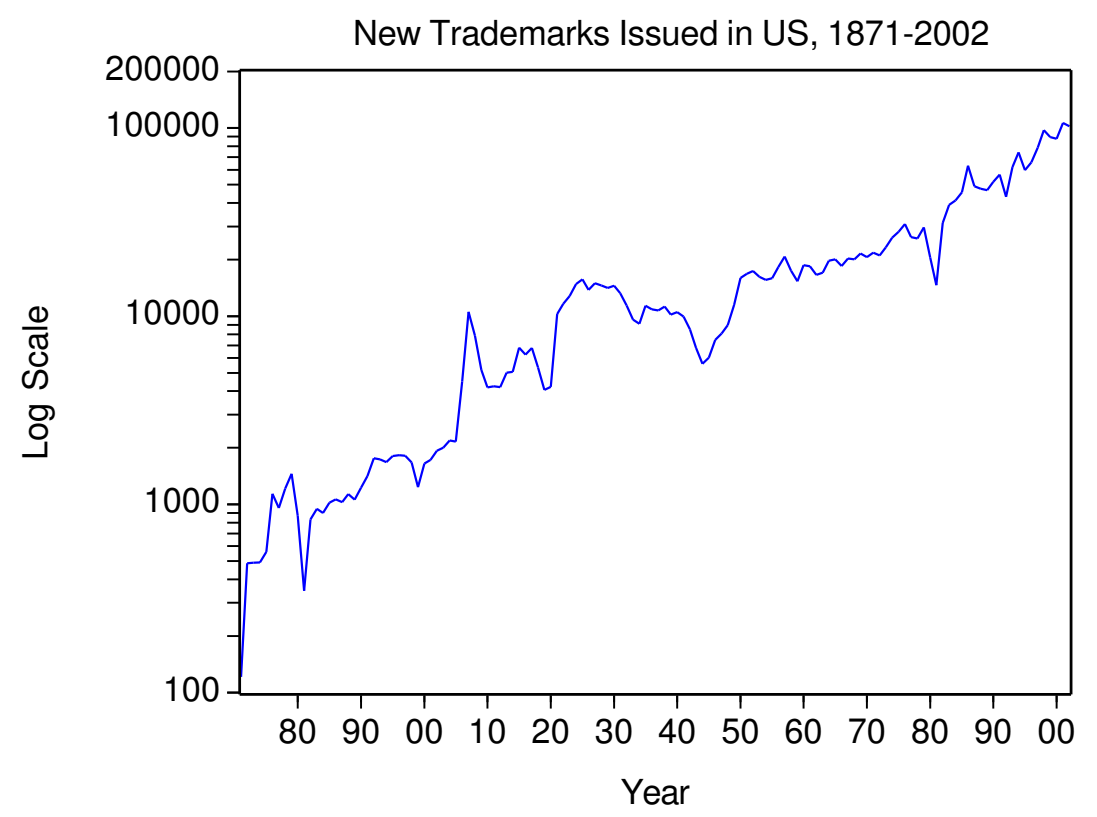

Figure 2: Number of New Trademarks Issued in United States 1871-2002. Source: Historical Statistics of the United STATES.

level of disaggregation are probably substantially larger."13

\subsubsection{Economic Fluctuations and Growth in Brands and Quality}

Especially relevant to this analysis is evidence of procyclical variety growth. A number of papers present direct evidence of procyclical product introduction (see, e.g., Broda and Weinstein, 2007; Axerloglou, 2005; Divinney, 1990; and Yorukoglu, 2000, among others). For example, Broda and Weinstein (2007) report that "net product creation is strongly procyclical," rising significantly in periods when consumption growth is high. Significantly, Broda and Weinstein (2006) infer from their data that variety growth is concentrated in low elasticity sectors. Broda and Weinstein (2007) find that new products take market share from existing ones. Taking this as evidence of quality improvements, they infer "substantial quality upgrading" in booms. According to the theory of revealed preference, welfare must rise in such a case.

Focussing on cyclical variation in the number of new trademarks, Yorukoglu (2000) studies variation in trademark registration over the business cycle and finds it strongly procyclical. Figure 3 dis-

\footnotetext{
${ }^{13}$ These statistics are for goods at the five digit level, which represent distinct products. There are 1848 five digit products in the United States.
} 


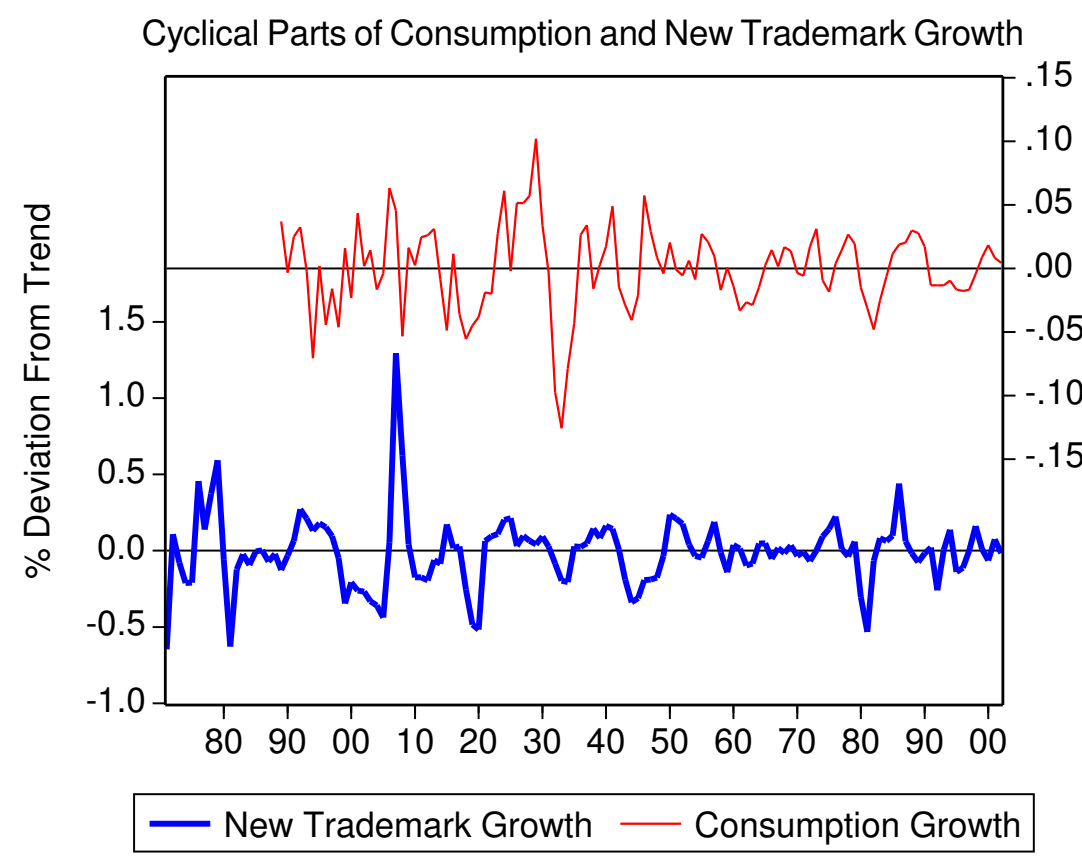

Figure 3: Cyclical Components of Consumption Growth and New Trademark Growth: UNITED STATES 1871-2002

SOURCE: HistoricAl STATISTICS OF THE United States.

plays the percentage deviation of new trademark registration growth from a Hodrick-Prescott trend. Two important points emerge from the figure. First, the variation of trademark registration from trend is high and often as large as fifty percent. For instance, Figure 2 shows that the level of trademark registration during the 1980s recession fell to levels prevailing in the 1940's. Second, there is pronounced covariation between trademark and consumption growth. Because the deviations from trend for trademark growth are more pronounced, variation in aggregate consumption growth masks variation in consumption services.

Examining product introductions advertised in the Wall Street Journal between 1984-1993, Axarloglou (2005) reports evidence of procyclical variety growth. More importantly, he reports that the correlation between these new product introductions and new trademark registration is .83suggesting Figure 3 reflects overall trends in new product introduction. In a similar study, Devinney (1990) provides evidence that firms introduce new products mostly at the beginning of the business cycle. Another source of cyclical variety growth is imports. Melitz and Ghironi (2007) point out that cross-country evidence indicates a strong correlation between imports and the number of imported 
varieties. Because imports are procyclical, this again indicates procyclical variety growth. Midrigan (2007) discusses product creation over the Argentinian currency crisis and observes that, during the crisis the rate of net product creation is as high as 19 percent, but a year later drops to -8 percent. Other more suggestive pieces of evidence include the fact that mark-ups are strongly countercyclical, suggesting greater firm entry and more competition; and the fact that advertising is strongly procyclical (Molinari and Turino, 2006).

In addition, a number of authors have stressed the procyclical nature of entry and business formation (see, e.g., Cooper and Chatterjee, 1993; Jovanovic, 2003; Devereux, Head, and Lapham, 1996). Using detrended data from the United States, Corsetti and Bergin (2001) report a correlation of net business formation and GDP of .73; and a correlation of the number of new incorporations with GDP of .53. According to Chatterjee and Cooper (1993), the number of firms in all industries fell 10 percent during the Great Depression, while in manufacturing the number of firms fell by over 33 percent. Moreover, Broda and Weinstein (2007) find that, after every four years, about twenty percent of expenditure is on products produced by new firms.

\subsubsection{Economic Fluctuations and Group Growth}

In contrast to brand and quality growth, there is little reason to expect significant covariation of product group growth with GDP over the business cycle. First, these products represent fundamentally new technological innovations, suggesting group growth is relatively stable. By construction, these are goods whose expenditure share rises when their prices rises, so must goods realistically do not fall in this category. Second, firms routinely publicize the development of new groups-such as cellphones-years in advance. Third, because demand for groups is inelastic, demand for new product groups is largely independent of economic fluctuations. Unlike the case of brands, there is no strong incentive to release these products in booms; for instance, a firm introducing a new cancer vaccine would likely release it irrespective of the stage of the business cycle. Indeed, firms might release new groups upon development to avail of a "first mover advantage." Furthermore, purchases of groups are often on an ongoing basis. For example, the purchase of new medical treatments or larger, better 
equipped homes is incorporated in insurance premia and mortgage payments, respectively. For all these reasons, group growth most likely acyclical or moderately procyclical. Broda and Weinstein (2007), for example, treat group growth as acyclical.

\subsection{Quantifying Welfare Effects of Variety Growth}

How much does variety matter for welfare? Significantly, the gains to increasing brand and quality variety have been successfully used in various fields of economics to explain large-scale phenomena. According to the new trade theory, for example, a love of variety is the prime reason for intraindustry trade (Krugman, 1979): consumers valuing different brands of goods is the prime reason for intraindustry trade (often in the face of large transport costs). Relatedly, Krugman (1991) emphasizes that greater variety in cities raises effective wages and is a driving force behind agglomeration; as such, the fact people pay large premia to live in cities testifies to a large love of variety. More generally, most economists have a benign view of monopolistic competition, maintaining that the associated variety gains counter the inefficiencies associated with this market structure.

Most studies use markups, and hence the degree of market power, to infer welfare gains from increasing variety. Because higher markups—commonplace in the industrial organization literatureindicate more inelastic demand, they suggest a greater love of variety. ${ }^{14}$ Yet for the most part, the consumer price index underestimates the welfare gains to new goods. Reviewing current methods in accounting for new goods, quality change and new outlets, Hausman (2003) argues that such methods are "severely inadequate." Likewise, Broda and Weinstein (2007) maintain that the net gains to product creation and destruction are largely unaccounted for.

\subsubsection{Quantifying Welfare effects}

Despite data limitations, a number of micro studies have attempted to quantify the welfare gains to greater brand variety. In a study of the market for breakfast cereals-a market with many close

\footnotetext{
${ }^{14}$ Yet markups are an imperfect measure of the welfare gains from variety. For instance, an increase in competition would likely reduce markups, but this hardly suggests the welfare gains from variety have fallen. In addition, lower search costs and quality increases also represent a gain to the introduction of easily substitutable, even identical varieties, but do not show up in markups.
} 
substitutes-Hausman (1997) reports: "I find that the virtual price is about twice the actual price of Apple-Cinnamon Cheerios and that the increase in consumer surplus is substantial." And concluding his study, he remarks: "I also find that consumers highly value new goods, which provide significant consumer surplus despite the existence of other brands which compete closely with the new brand." Nevo (2002) finds similar figures in the cereal industry. Brynjolfsson (1996) estimates the consumer surplus associated with spending on IT to be about three times the level of spending on IT. In a study of the market for online books at Amazon.com, Brynjolfsson, Hu and Smith (2003) estimate a ratio of consumer surplus to revenue of between 1.25 and 1.75. Additionally, they find that the increased product variety offered by online bookstores enhanced consumer welfare by $\$ 731$ million to $\$ 1.03$ billion in 2000. On the gains to greater imports, Broda and Weinstein (2006) estimate that consumers in the United States would be willing to pay 2.7 percent of GDP or $\$ 280$ billion a year to have access to the range of import products available in 2001 (as opposed to 1972). Notably, these estimates are for highly substitutable products, so most likely underestimate the welfare gains to variety.

As for the welfare gains to quality increases, Bils (2004) shows that quality growth for durables has averaged at least 5.8 percent a year, more than double the rate implied by CPI measurement. ${ }^{15}$ Berndt and Griliches (1990) report a thirty per cent fall in the quality-adjusted price of personal computers per annum from 1982-1988. Hausman (1999) shows that there are large welfare gains to the introduction of cell-phones and finds that the quality adjusted price of cell-phones fell by 90 percent from 1989 to 1998. Meanwhile, Nordhous (1997) quantifies the enormous fall in the quality-adjusted price of light; his estimates show that traditionally constructed light indices overestimate the rate of inflation of the price of lighting services over the period since 1800 by an average of 3.6 percent a year.

\subsection{Empirical Evidence on Cyclical Marginal Utility Growth}

From Eq. (6), marginal utility growth is given by:

$$
\frac{V^{\prime}(C)}{V^{\prime}(C)}=\zeta \frac{\dot{n}}{n}+v(1-\theta) \frac{\dot{m}}{m}+\gamma(1-\theta) \frac{\dot{A}}{A}-\theta \frac{\dot{C}}{C} .
$$

\footnotetext{
${ }^{15}$ These products comprised 80 percent of spending on consumer durables in the United States.
} 
Whether variety growth causes marginal utility to rise or fall relative to trend over the business cycle depends on the relative magnitudes and the respective growth rates and tastes for brand, quality and groups. As already noted, group growth raises marginal utility, while brand and quality growth reduce it. But is there any concrete evidence confirming whether marginal utility is higher or lower in a boom? One important piece of evidence is the procyclicality of luxury goods expenditure. As pointed out by Aït-Sahalia, Parker, and Yogo (2004), sales of luxury goods are strongly procyclical. This can be seen in Figures 4 and 5, which display plots of luxury sales growth together with the consumption growth of services and nondurables in the United States over the period 1961-2001. According to Aït-Sahalia et al., donations to charities and the price increases of rare goods are also procyclical. Again, such observations suggest marginal utility is lower in a boom, not higher. Although luxury goods are excluded from the model, this is merely for analytical convenience rather than for realism. To incorporate luxury goods, one could simply posit a luxury brand in each group, with a price exceeding unity. ${ }^{16}$

A simple example conveys the main intuition. Suppose there are two composite commodities in each group: luxuries and "everything else." Set the price of ordinary goods, $o$, to unity and the price of luxury goods, $l$, to $p_{l}>1$. In view of the figures, assume further that luxury sales increase in a boom. Now, denote the marginal utility of income by $M U$ and the marginal utility of good $i$ by $M U_{i}$. In view of the evidence in Figure 4, in a recession: $M U=\frac{M U_{o}}{p_{0}}>\frac{M U_{l}}{p_{l}}$. In contrast, for a boom the solution is interior: $\frac{M U_{o}}{p_{0}}=\frac{M U_{l}}{p_{l}}$. Because $M U_{o}$ must fall in a boom to ensure equality and yield an interior solution, this implies marginal utility growth falls disproportionately in booms. That this occurs suggests that the effect of increasing brand and quality dominates the increase in group growth. Specifically, since $\frac{V^{\prime}(C)}{V^{\prime}(C)}<0$, and $-\theta \frac{\dot{C}}{C}$ is relatively small, Eq. (19) suggests $\zeta \frac{\dot{n}}{n}<v(1-\theta) \frac{\dot{m}}{m}+\gamma(1-\theta) \frac{\dot{A}}{A}$.

\footnotetext{
${ }^{16}$ With such homothetic preferences, we would have to specify that marginal utility is non-infinite at zero consumption.
} 


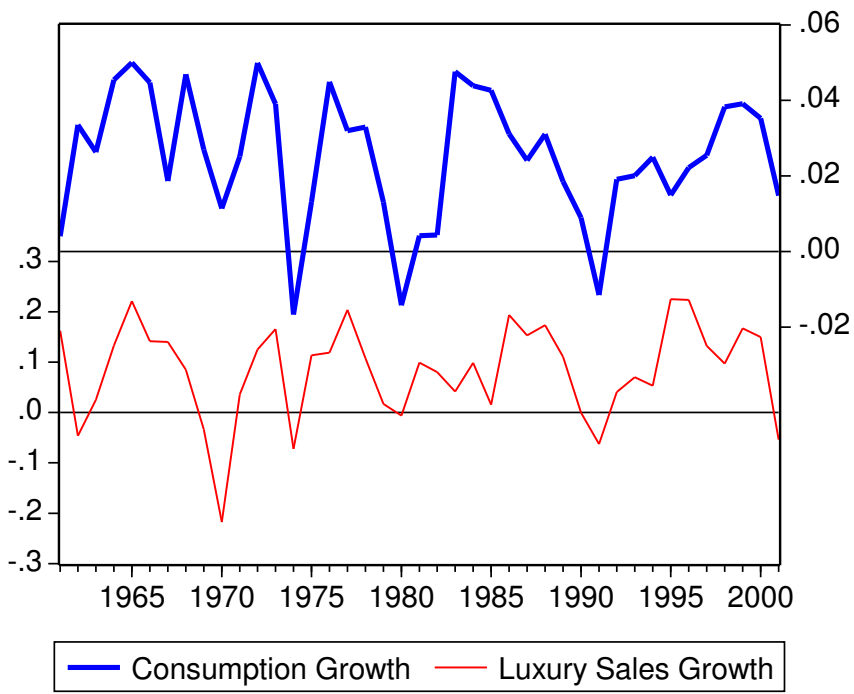

Figure 4: LuXury SAlEs Growth AND CONSUmption Growth: United STATES DATE. SOURCE: AIt-SAHALIA, PARKER, AND Yogo (2004)

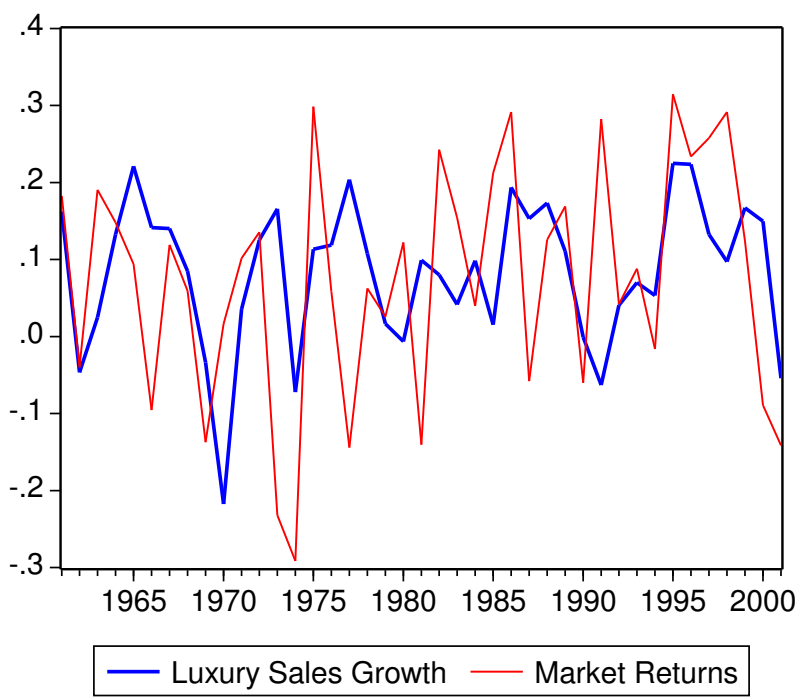

Figure 5: LuXury SAlES GRowth AND MARKet Returns: United States. SOURCE: AIt-SAHALIA, PARKER, AND Yogo (2004) 


\subsection{Calibration of Parameters}

In this section, I present a calibration. All data are in percentage terms and from the United States. Annual arithmetic returns are $r_{f}=2, r-r_{f}=6$. Average consumption growth is $g_{c}=2, \sigma_{g_{c}}=3.2$, $\sigma_{r-r_{f}}=19$, and $\rho_{r, g_{c}}=.4$. To calibrate the model, I set the following baseline parameters: $\theta=4$, $\rho=3, \sigma_{g_{m}}=5, \sigma_{g_{A}}=5, \sigma_{g_{n}}=1, \gamma=1, v=.3, \rho_{g_{m}, g_{C}}=.7, \rho_{g_{A}, g_{C}}=.7 \rho_{g_{n}, g_{C}}=.3, \rho_{r, g_{A}}=.7$, $\rho_{r, g_{m}}=.7, \rho_{r, g_{n}}=.3, \rho_{g_{m}, g_{A}}=.7, \rho_{g_{n}, g_{m}}=.3, \rho_{g_{m}, g_{C}}=.7, \rho_{g_{A}, g_{C}}=.7, \rho_{g_{n}, g_{C}}=.3, \rho_{r, g_{m}}=.7$, $\rho_{r, g_{A}}=.7, \rho_{r, g_{n}}=.3, \rho_{g_{m}, g_{A}}=.7$, and $\rho_{g_{n}, g_{m}}=.3$. For comparison, I also perform a calibration with $\theta=3$ and $\rho=2$.

\subsubsection{Data Sources and Calibration}

Data on the standard deviation of annual returns is from Constantinides (2002) and extends from 1872 to 2000 . Annual consumption data on nondurables and services from 1890-2000 is from Robert Shiller's website. Barro (2006) observes that measures of risk aversion, $\theta$, between 2 and 5 are standard in finance. These figures are also roughly consistent with measures of the intertemporal subsitution, $\frac{1}{\theta}$, noted earlier. The discount rates are standard for annual data.

The evidence cited earlier suggests significant variation in brand and quality growth. To the extent that many goods are not trademarked, variation in trademarks likely reflects variation of new product introductions (Axerloglou, 2003). As already noted, Broda and Weinstein (2007) find evidence of "substantial quality upgrading" in booms, indicating significant variability in quality growth. Based on this evidence, I set $\sigma_{g_{m}}=5$ and $\sigma_{g_{A}}=5$ as a baseline. These figures are about 2 percent higher than the standard deviation of consumption growth, and given that consumption growth is traditionally regarded as relatively stable, these estimates are probably conservative. Given little expected volatility in group growth, I set $\sigma_{g_{n}}=1$. Correlations of .7 between returns and each of both brand and quality growth reflect the strong procyclicality of product introductions noted earlier. Since group growth, if anything, is probably mildly procyclical, I set $\rho_{r, g_{n}}=.3$,

The taste for brands, $v$, answers the question: keeping quality constant, if the number of brands in a group increases by one percent, what is the percentage increase in consumption services? As is 
standard, I infer $v$ from elasticities of demand; taking elasticities of demand to deduce welfare gains implies $v=\frac{1}{1-\alpha} \cdot{ }^{17}$ Steinssen and Nakamura (2007) use an elasticity of demand of 4 to "roughly match estimates of the elasticity of demand from the industrial organization and trade literature." By comparison, Rotemberg and Woodford (1995) favor markups from 20 to 40 percent, corresponding to elasticities of demand of 3.5 to $6 .{ }^{18}$ Based on this evidence (i.e., $\frac{1}{1-\alpha}=4.5$ ), I take an elasticity of 4.5 as a baseline, implying that $\alpha=\frac{3}{4}$ and $v=.3$.

Because $c_{j t}=m_{t}^{v} A_{t}^{\gamma} C_{t}$ in equilibrium, the taste for quality answers the question: keeping the number of brands constant, if quality, $A_{t}$, increases by one percent, what is the percentage increase in consumption services? As in Hummels and Klenow (2005), I set $\gamma=1$. Yet this is probably conservative, since evidence from price data suggests consumers value quality increases above quantity increases; for example, consumers routinely pay disproportionately more for luxury goods such as first class air travel.

Finally, to calibrate $\zeta$, recall from Eq. (16) the condition for stable labor hours: $(\theta-1) g_{c}-v(1-$ $\theta) g_{m}-\gamma(1-\theta) g_{A}=\zeta g_{n}$. As crude approximations, set $g_{c}=2, g_{m}=2.5, g_{A}=2$, and $g_{n}=1.35$. For $\theta=3$, this implies $\zeta \approx 7$, which I take as a baseline.

\subsubsection{Calibration of the Risk-Free Rate and Equity Premium}

Tables (1) and (2) present the calibrations of the expressions for the expected risk-free rate, Eq. (17), and the expected equity premium, Eq. (18), for the parameter values in each column.

Column 1 displays the predictions from the standard one-good CCAPM. Absent a love for variety, we get the well-known puzzles, highlighted in the first column. Columns $2-5$ show the effects of increasing the volatility of brand and quality growth. For the baseline calibration, Column 2 shows that the risk-free rate falls from 10 to .5 , while the equity premium rises from .9 to 3.2 . By comparison,

\footnotetext{
${ }^{17}$ To see this, in the standard Dixit-Stiglitz model $c_{j t}=m_{t}^{\left(\frac{1}{\alpha}-1\right)} A_{t}^{\gamma} C_{t}$, corresponding to $m_{t}^{v} A_{t}^{\gamma} C_{t}$ in my setup. However, the Dixit-Stiglitz function is a convenient modelling device, not a literal description of the world.

${ }^{18}$ Tellis (1988) surveys the marketing literature and reports an average price elasticity of 1.76. Broda and Weinstein (2007) cite evidence from marketing studies showing that the typical demand elasticity found between different products of the same brand lies in the range of 4 to 7. Broda and Weinstein (2006) report an average elasticity of demand of 4.2 for the United States. In a study of the welfare gains to variety growth, Feenstra (1994) obtains elasticities between 3 and 8 for various goods; for example, he reports estimates of 6.23 for shoes, 4.21 for sheets, and 2.96 for typewriters.
} 
Table 1: Calibration of Expected Returns when Risk Aversion $\theta=4$ and $\rho=3 \%$

\begin{tabular}{|c||c|c|c|c|c|c|c|c|c|c|c|c|c|c|}
\hline \hline & $(1)$ & $(2)$ & $(3)$ & $(4)$ & $(5)$ & $(6)$ & $(7)$ & $(8)$ & $(9)$ & $(10)$ & $(11)$ & $(12)$ & $(13)$ & $(14)$ \\
\hline \hline$v$ & .3 & .3 & .3 & .3 & .3 & .6 & .3 & .3 & .3 & .3 & .3 & .3 & .3 & .3 \\
$\gamma$ & 1 & 1 & 1 & 1 & 1 & 1 & .5 & 1 & 1 & 1 & 1 & 1 & 1 & 1 \\
$\zeta$ & 7 & 7 & 7 & 7 & 7 & 7 & 7 & 7 & 7 & 7 & 7 & 7 & 7 & 7 \\
$\sigma_{g_{m}}$ & $\mathbf{0}$ & $\mathbf{5}$ & $\mathbf{4}$ & $\mathbf{6}$ & 8 & 5 & 5 & 0 & 5 & 5 & 5 & 5 & 5 & 5 \\
$\sigma_{g_{A}}$ & $\mathbf{0}$ & $\mathbf{5}$ & $\mathbf{4}$ & $\mathbf{6}$ & 8 & 5 & 5 & 5 & $\mathbf{0}$ & 5 & 5 & 5 & 5 & 5 \\
$\sigma_{g_{n}}$ & $\mathbf{0}$ & 1 & 1 & 1 & 1 & 1 & 1 & 1 & 1 & $\mathbf{0}$ & 3 & 1 & 1 & 1 \\
$\rho_{r, g_{m}}$ & .7 & .7 & .7 & .7 & .7 & .7 & .7 & .7 & .7 & .7 & .7 & .5 & .8 & .7 \\
$\rho_{r, g_{A}}$ & .7 & .7 & .7 & .7 & .7 & .7 & .7 & .7 & .7 & .7 & .7 & .5 & .8 & .7 \\
$\rho_{g_{n}, g_{m}}$ & .3 & .3 & .3 & .3 & .3 & .3 & .3 & .3 & .3 & .3 & .3 & .3 & .3 & .8 \\
\hline \hline $\mathbf{r}_{\mathbf{f}}$ & $\mathbf{1 0}$ & .5 & 1.6 & -.7 & -3.7 & -.7 & 2.3 & 1.5 & 3.5 & 0 & .2 & .5 & .5 & 1.2 \\
\hline \hline $\mathbf{r}-\mathbf{r}_{\mathbf{f}}$ & .9 & 3.2 & 2.6 & 3.7 & 4.7 & 3.8 & 2.2 & 2.6 & 1.2 & 3.6 & 2.4 & 2.4 & 3.5 & 3.2 \\
\hline \hline
\end{tabular}

NOTE: The table gives the expected rates of return for the parameter values in the cells. The expected risk-free rate is from Eq. (17), and the expected equity premium is from Eq. (18). Standard deviations and rates of return are in percentage terms.

when $\theta=3$, the risk-free rate falls to 1.7 , and the premium rises to 2.1. More generally, a comparison of Tables 1 and 2 shows that increasing risk aversion has a similar effect in all columns. By raising the aversion to fluctuations in marginal utility, higher risk aversion increases the expected equity premium. Meanwhile, by increasing the variability of marginal utility, higher risk aversion raises precautionary savings and reduces the risk-free rate. Except for the case when $\theta=4$ and $\sigma_{g_{m}}=$ $\sigma_{g_{A}}=.8$, all the estimates of the risk-free rate are in a reasonable range. But increasing volatility to $\sigma_{g_{m}}=\sigma_{g_{A}}=.8$ induces such a large rise in precautionary savings that the risk-free rate falls to an unrealistically low level, $-3.7 \%$.

Columns 6 and 7 display the effects of changing the taste for brands and quality. Because it makes marginal utility more variable, doubling the taste for brands in Column 6 has the same qualitative effect as increasing brand growth volatility. Reducing the taste for quality from 1 to .5 has the opposite qualitative effects, but higher quantitative effects. When $\theta=4$, the expected equity premium falls by one percent. Since consumers value proportional changes in quality more than brands, changes on the quality margin have a larger impact on the results.

Columns $8-10$ show the effect of eliminating volatility in each of brand, quality, and group growth. Given that these changes reduce the variability of marginal utility growth, they reduce the 
Table 2: Calibration of Expected Returns when Risk Aversion $\theta=3$ and $\rho=2 \%$

\begin{tabular}{|c||c|c|c|c|c|c|c|c|c|c|c|c|c|c|}
\hline \hline & $(1)$ & $(2)$ & $(3)$ & $(4)$ & $(5)$ & $(6)$ & $(7)$ & $(8)$ & $(9)$ & $(10)$ & $(11)$ & $(12)$ & $(13)$ & $(14)$ \\
\hline \hline$v$ & 0 & .3 & .3 & .3 & .3 & .6 & .3 & .3 & .3 & .3 & .3 & .3 & .3 & .3 \\
$\gamma$ & 0 & 1 & 1 & 1 & 1 & 1 & .5 & 1 & 1 & 1 & 1 & 1 & 1 & 1 \\
$\zeta$ & 0 & 7 & 7 & 7 & 7 & 7 & 7 & 7 & 7 & 7 & 7 & 7 & 7 & 7 \\
$\sigma_{g_{m}}$ & 5 & 5 & 4 & 6 & 8 & 5 & 5 & 0 & 5 & 5 & 5 & 5 & 5 & 5 \\
$\sigma_{g_{A}}$ & 5 & 5 & 4 & 6 & 8 & 5 & 5 & 5 & 0 & 5 & 5 & 5 & 5 & 5 \\
$\sigma_{g_{n}}$ & 1 & 1 & 1 & 1 & 1 & 1 & 1 & 1 & 1 & 0 & 3 & 1 & 1 & 1 \\
$\rho_{r, g_{m}}$ & .7 & .7 & .7 & .7 & .7 & .7 & .7 & .7 & .7 & .7 & .7 & .5 & .8 & .7 \\
$\rho_{r, g_{A}}$ & .7 & .7 & .7 & .7 & .7 & .7 & .7 & .7 & .7 & .7 & .7 & .5 & .8 & .7 \\
$\rho_{g_{n}, g_{m}}$ & .3 & .3 & .3 & .3 & .3 & .3 & .3 & .3 & .3 & .3 & .3 & .3 & .3 & .8 \\
\hline \hline $\mathbf{r}_{\mathbf{f}}$ & 7.4 & 1.7 & 2.2 & 1.1 & -.3 & 1.1 & 2.5 & 2.1 & 3.1 & 1.4 & .9 & 1.7 & 1.7 & 2.2 \\
\hline \hline $\mathbf{r}-\mathbf{r}_{\mathbf{f}}$ & .7 & 2.1 & 1.7 & 2.4 & 3.1 & 2.5 & 1.4 & 1.7 & .7 & 2.5 & 1.3 & 1.6 & 2.3 & 2.1 \\
\hline \hline
\end{tabular}

equity premium and raise the risk-free rate. Comparing Columns 8 and 9 , we see that reducing the variability of quality growth has larger quantitative effects: it reduces the equity premium by two percent when $\theta=4$ and by 1.5 percent when $\theta=3$. In contrast, eliminating volatility of group growth raises the equity premium; for example, in the baseline case when $\theta=4$, the equity premium rises by .4 percent. Tripling the volatility of group growth from 1 to 3 percent in Column 11 reduces the equity premium by .8 percent.

Raising the volatility of group growth has two effects. One consequence is to increase precautionary savings for the usual reasons. But because changes in $n$ and each of $m$ and $A$ are positively correlated, they have opposing effects on marginal utility. As a result, their comovement acts as a hedge, reducing variation in expected marginal utility, thereby lowering precautionary savings and the risk-free rate. In Column 10, this latter force dominates, so reducing the volatility causes the risk-free rate to fall. But in Column 11, raising group growth causes precautionary savings to rise, thereby lowering the risk-free rate.

Column 12 displays the effects of reducing the correlation between returns and each of brand and quality growth. Again, this has the same qualitative effect on the equity premium as reducing the respective volatilities. Reducing correlations from .7 to .5 reduces the premium by an average .6 percent. But since the level of the risk-free rate is independent of the characteristics of equity, this change has no effect on the risk-free rate. Likewise, raising correlations between equity returns and 
brand and quality growth from .7 to .8 raises the equity premium by .3 percent in both cases. Finally, Column (14) shows that increasing the correlation between $n$ and $m$ growth raises the risk-free rate, but has no effect on the equity premium. As already noted, positive correlation between $n$ and $m$ growth act as a hedge, making expected marginal utility less volatile. This reduces savings and raises the risk-free rate. But given that this change affects both equities and the risk-free rate, it has no effect on the expected equity premium. Finally, although not shown in the tables, changes in the discount rate have no effect on the expected equity premium, but change the risk-free rate one-for-one.

\subsection{Discussion}

A reasonable interpretation of the results is that the predicted equity premium is in the range of $2-3 \%$, while the expected risk-free rate is around $1.5 \%$. Hence, for reasonable parameter values, the calibrations suggest that the procyclicality of brand and quality growth increases the expected equity premium. Meanwhile, group growth over time counters diminishing marginal utility, promoting savings and ultimately reducing the risk-free rate. For reasonable parameter values, the risk-free rate is in the ballpark of historical estimates. Therefore, incorporating changes in variety into the CCAPM works against both the equity premium and risk-free rate puzzles.

Yet the model fails to predict a premium of approximately 6 percent. This could be explained in a number of ways. First, the model is stark, so other features would raise the premium further. In addition, certain changes to the baseline calibration—-for example, raising the taste for qualitywould also increase the expected premium. Second, stock market volatility is substantial, making a precise estimate of the premium difficult. Third, and most importantly, explaining a $6 \%$ premium is only meaningful if this was the actual expected return. Significantly, many economists have recently lowered their estimates of the equity premium. In particular, it is unclear that economic (and hence dividend) growth would be so strong in the postwar period. For example, Cochrane (2008) notes: “many economists' beliefs about the size of the equity premium are......down to 2 or 3 percent or less." ${ }^{19}$ Given that a fall in the expected equity premium has to show up as a higher realized equity

\footnotetext{
${ }^{19}$ Blanchard (1993) estimates an equity premium of approximately 2 percent. He attributes a higher earlier premium to fading memories of the Great Depression. Reviewing a number of recent studies on this issue, Jagannathan and McGrattan
} 
premium over some horizon, these views have substantial merit. Fama and French (2002), for example, stress that price appreciation was much higher than dividend and earnings growth in the postwar period. Hence, given a stable long-run dividend price ratio, realized capital gains were therefore greater than expected. Examining the data, they calculate an expected equity premium of between 2.55 percent and 4.32 percent. Pursuing the same reasoning, Bernstein (1997) estimates a premium of 3 percent. Consistent with these views, Siegel (1993) documents that the expected equity premium was lower in the United States last century. Accounting for these views, the calibrated values for the equity premium seem more reasonable. And, moreover, the model matches figures for the risk-free rate reasonably well—and this is the return that is most accurately measured.

In addition, the fact that the model is consistent with the stylized fact of relatively stable labor hours over time is evidence in its favor. Fundamentally, all savings derive from labor, so this internal consistency is an attractive feature of the model. In contrast, the standard model predicts a steadily falling labor supply over time. Hence, if predictions for labor supply were also added to the tables, the model here would also compare favorably. Another piece of evidence is an empirical study by Normandin and St-Amour (1996), who show that taste shocks can resolve the equity premium puzzle and claim that "taste risks are quantitatively important in capturing excess returns movements." Although in their study the source of the taste shocks is unknown, the analysis here provides a natural interpretation.

Two more speculative pieces of evidence favor the model. Siegel (1993) points out that there was no equity premium two centuries ago, and in particular, that the risk-free rate was markedly higher. Clark (2007) also points out how the risk-free rate fell upon the onset of sustained economic growth rates - the opposite prediction of the standard model. Moreover, Goetzmann and Jorian (2002) show that the equity premium is higher for countries with longer time series, which are typically more developed countries. To the extent that more developed economies are more susceptible to the dynamics outlined here, the model predicts a lower risk-free rate and a higher equity premium for

(2002) report that "all of these studies agree that the US equity premium is currently lower than it has been historically." Goetzmann and Jorian (1998) contend that survival bias raises the equity premium by a factor of two and estimate an expected premium of around 3.5 percent. Using international data, Dimson, Marsh and Staunton (2002) find lower equity returns in the early 20 th century than in the latter part. 
such countries.

\section{Conclusion}

This paper has explored the effects of introducing variety growth into the consumption capital asset pricing model. In the model, consumers have a love of variety and new goods come on stream over time. Procyclical brand and quality growth make marginal utility more volatile over the business cycle and therefore raise the expected equity premium. Meanwhile, group growth over time increases the incentive to save and ultimately reduces the risk-free rate. The calibration suggests that risk to the level of consumption is a relatively small part of consumption risk over the business cycle. More important is the role of variety risk —in particular, risk to brand and quality growth—which, for reasonable parameter values, accounts for a large part of the equity premium. For this reason, the model also casts doubt on the trivial welfare costs—i.e., the changes in real consumption-of business cycles estimated by Lucas (1988). Consistent with the data, the model also predicts stable interest rates and predicts a sizable equity premium even in the face of a low correlation between consumption growth and equity returns. But the intent of the model is not to substitute for other solutions to asset pricing puzzles. Rather, the framework supplements any "consumption-based" solution—such as habit persistence or consumption risks over the long run-to asset pricing puzzles.

The framework introduces variety growth into a model of intertemporal choice and therefore has broad implications for dynamic macroeconomic models - and especially for savings behavior. Moreover, the model is consistent with the stylized fact of stable labor hours over time. Because investments ultimately stem from the labor market, this internal consistency is an attractive feature of the model.

Although the model is set in the context of partial equilibrium, modifying the model to incorporate a production sector would make an interesting extension. Product innovation and "creative destruction" lie at the heart of modern theories of growth, so the framework here has a natural complement on the production side. For instance, the constant real interest rate is consistent with an $A K$ type model, where new and improved intermediate goods offset diminishing returns to capital. Meanwhile, over 
the business cycle procyclical variety growth would raise the real wage, leading to procyclical labor supply.

An interesting question is whether the model can shed light on the equity volatility puzzle. Within the framework of the model, this could be explained by an increase in the conditional volatility of brand and quality growth in recessions. In turn, this time-varying systematic risk would induce a (conditional) countercyclical equity premium, as borne out in the data-thereby inducing price variation. Furthermore, any model of the equity premium over time also makes predictions about the cross-sectional variation in returns. For example, the higher expected returns of small firms is a robust feature of the data. If performance of small firms is correlated with variety growth—as seems likely, since new firms are typically small—this might provide a rationale for the small-firm effect. But more work is needed to test these implications.

Lack of precise data on variety growth and the associated welfare gains is a shortcoming of the analysis. Yet casual observation suggests people care a lot about what they buy. And product development is a central concern of firms. The idea of "love of variety" has also successfully explained economic phenomena in such fields as trade theory and industrial organization. Hence, although the underlying mechanism seems reasonable, more rigorous empirical work is needed to sharpen the estimates presented here. 


\section{References}

[1] Aït-Sahalia, Y., J. Parker, and M. Yogo. 2004. “Luxury Goods and the Equity premium.” Journal of Finance, 59: 2959-3004.

[2] Attanasio, O. P. and Weber, G. 1995. "Is Consumption Growth Consistent with Intertemporal Optimization? Evidence from the Consumer Expenditure survey.” Journal of Political Economy 103, 112157.

[3] Axarloglou, K. 2003. "The Cyclicality of New Product Introductions.” Journal of Business 76: 29-48.

[4] Barro, R. 2006. "Rare disasters and asset markets in the twentieth century." Quarterly Journal of Economics 121 : 823-866.

[5] Barro, R, and R. King. 1984. "Time-separable preferences and intertemporal substitution models of business cycles."

[6] Benassy, J.P. 1996. “Taste for Variety and Optimum Production Patterns in Monopolistic Competition.” Economics Letters, 52, pp. 41-47.

[7] Bergin, P. R., and G. Corsetti. 2005. “Towards a Theory of Firm Entry and Stabilization Policy.” National Bureau of Economic Research Working Paper 11821.

[8] Bernard, A. B., S. J. Redding, and P. K. Schott. 2006. "Multi-Product Firms and Product Switching." National Bureau of Economic Research Working Paper 12293.

[9] Berndt, E. R., and Griliches, Z. (1990), ’Price Indexes for Microcomputers: An Exploratory Study," Working Paper 3378, National Bureau of Economic Research, Cambridge, MA.

[10] Bernstein, P. L. 1997. "What Rate of Return Can You Reasonably Expect... or What Can the Long Run Tell Us about the Short Run?" Financial Analysts Journal, 53(2).

[11] Bilbiie, F., F. Ghironi and M. Melitz. 2006. "Monopoly Power and Endogenous Variety in Dynamic Stochastic General Equilibrium models.” Mimeo Harvard University.

[12] Bilbiee, F., F. Ghirino, and M. Melitz. 2007. "Endogenous Entry, Product Variety, and Business Cycles.” NBER Macroeconomics Annual.

[13] Bils, Mark. 2004. "Measuring Growth from Better and Better Goods." National Bureau of Economic Research Working Paper 10606.

[14] Bils, M., and P. J. Klenow. 2001a. “The Acceleration in Variety Growth.” American Economic Review 91: $274-280$.

[15] Bils, Mark, and Peter J. Klenow. 2001b. “Quantifying Quality Growth.” American Economic Review, 91, $1006-1030$.

[16] Blanchard, Olivier Jean. 1993. "Movements in the equity premium." Brookings Papers on Economic Activity, Macroeconomics 2: 75118.

[17] Bresnahan T. and R. J. Gordon, eds. 1997. The Economics of New Goods. Chicago: University of Chicago Press.

[18] Breeden, D. 1979. “An Intertemporal Asset Pricing model with Stochastic Consumption and Investment Opportunities." Journal of Financial Economics 7: 265-296.

[19] Broda, C. and D. Weinstein. 2006. "Globalization and the Gains from Variety." Quarterly Journal of Economics, Volume 121, Issue 2.

[20] Broda, C., and D. E. Weinstein. 2007. “Product Creation and Destruction: Evidence and Price Implications.” Mimeo, University of Chicago. 
[21] Brynjolfsson, Erik, Yu Hu, Michael Smith. 2003. Consumer Surplus in the Digital Economy: Estimating the Value of Increased Product Variety. Management Science, 49(11) 1580-1596.

[22] Brynjolfsson, Erik. 1996. “The Contribution of Information Technology to Consumer Welfare.” Information Systems Research, Vol. 7, No. 3 pp. 281-300.

[23] Cabral, L. 2000. Introduction to Industrial Organization. Cambridge: MIT Press.

[24] Campbell, J. Y. 2001. “Asset Pricing at The Millennium.” Journal of Finance 55: 1515-1567.

[25] Campbell, J. Y. 2003. “Consumption-Based Asset Pricing.” In G. M., Constantinides, M. Harris, and R. Stulz, eds., Handbook of the Economics of Finance. North-Holland Elsevier, Amsterdam, pp 803-887.

[26] Carroll, Christopher D. and Summers, Lawrence H., 1989. “Consumption Growth Parallels Income Growth: Some New Evidence”. National Bureau of Economic Research Working Paper 3090.

[27] Chatterjee, S., and R. Cooper. 1993. "Entry and Exit, Product Variety and the Business Cycle." National Bureau of Economic Research Working Paper 4562.

[28] Chetty, R., and A. Szeidl. 2007. "Consumption Commitments and Risk Preferences," The Quarterly Journal of Economics, MIT Press, vol. 122(2), pp 831-877.

[29] Clark G. 2007. A Farewell to Alms. Princeton: Princeton University Press.

[30] Cochrane, J. H. 2005 Asset Pricing. Princeton, NJ: Princeton University Press.

[31] Cochrane, J. H. 2008. "Financial Markets and the Real Economy.” In R. Mehra, ed., Handbook of the Equity Risk Premium. Elsevier, Amsterdam.

[32] Cochrane, J. H. 1999. "New Facts in Finance." Economic Perspectives, Federal Reserve Bank of Chicago 23(3): $36-58$.

[33] Constantinides, G. 2002. “Rational Asset Prices.” Journal of Finance, vol. 57, no. 4 (August):15671591.

[34] Cox, A. and Alm, J. 1997. “The Right Stuff”. Federal Reserve Bank of Dallas Annual Report.

[35] Devereux, M. B., A. C. Head, and B. J. Lapham. 1996. “Aggregate Fluctuations with Increasing Returns to Specialization and Scale.” Journal of Economic Dynamics and Control 20: 627-656.

[36] Devinney, T. M. 1990. "New products over the business cycle." Journal of Product Innovation Management 7: 26173.

[37] Dimson, E., P. Marsh, and M. Staunton. 2002. Triumph of the Optimists: 101 Years of Global Investment Returns. Princeton: Princeton University Press.

[38] Dixit, A. K., and J. E. Stiglitz. 1977. "Monopolistic Competition and Optimum Product Diversity.” American Economic Review 67: 297-308.

[39] Ebert and Griffin. 2006. "Business Essentials.” Fifth Edition. Prentice Hall.

[40] Epstein, L. G., and S. E. Zin. 1989. "Substitution, risk aversion, and the temporal behavior of consumption and asset returns: A theoretical framework.” Econometrica 57(4): 937-969.

[41] Fama, E. F., and K. R. French. 1993. "Common Risk Factors in the Returns of Stocks and Bonds." Journal of Financial Economics 33: 3-56.

[42] 1995. "Size and Book-to-Market Factors in Earnings and Returns." Journal of Finance, 50: 131155. 
[43] 1996. "Multifactor Explanations of Asset-pricing Anomalies." Journal of Finance, 51: 55-84.

[44] 2002. “The Equity Premium.” Journal of Finance, 57, 2:637-659.

[45] Feenstra, R. 1994. "New Product Varieties and the Measurement of International Prices." American Economic Review, 84(1), 157-177.

[46] Garber, Peter M., and Robert G. King. 1993. "Deep Structural Excavation? A Critique of Euler Equation Methods.” National Bureau of Economic Research Technical Working Paper 0031.

[47] Ghironi F., and Meltiz, M. 2007. "Trade Flow Dynamics with Heterogenous Firms.” American Economic Review, 97:2, 356-361.

[48] Grossman S., and Shiller R. 1981. "The Determinants of the Variability of Stock Market Prices." NBER Working Paper 0564.

[49] Hall, R. E. 1988. "Intertemporal substitution in consumption.” Journal of Political Economy 96(2): 339357.

[50] Hansen, L. P., and R. Jagannathan. 1991. "Implications of security market data for models of dynamic economies." Journal of Political Economy 99: 225-262.

[51] Hansen, L. P., and K. J. Singleton. 1983. "Stochastic consumption, risk aversion, and the intertemporal behavior of asset returns." Journal of Political Economy 91: 249-268.

[52] Hausman, Jerry A. 1999. "Cellular Telephone, New Products and the CPI." Journal of Business and Economic Statistics. 17:2, pp. 188-94.

[53] Hausman, J.A. 1997. "Valuation of New Goods Under Perfect and Imperfect Competition," in The Economics of New Products, T. F. Bresnahan and R. J. Gordon, eds. Chicago: University of Chicago Press.

[54] Hausman, J. 2003. "Sources of Bias and Solutions to Bias in the CPI". Journal of Economic Perspectives.

[55] Hummels, D. and P. J. Klenow, 2005. "The Variety and Quality of a Nations Trade." American Economic Review Vol. 95, No 3, pp. 704-723.

[56] Jagannathan, Ravi, Ellen R. McGrattan, and Anna Scherbina. 2000. “The Declining U.S. Equity Premium.” Quarterly Review, Federal Reserve Bank of Minneapolis, vol. 24, no. 4 (Fall):319.

[57] Jaimovich, N. 2004. "Firm Dynamics, Markup Variations, and the Business Cycle. Manuscript, Stanford University.

[58] Jorion, Philippe, and William N. Goetzmann. 1999. "Global Stock Markets in the Twentieth Century." Journal of Finance, 54 (3), 953-980.

[59] Jovanovic, B. and S. Lach. 1997. "Product Innovation and the Business Cycle." International Economic Review, Vol. 38, No. 1., pp. 3-22.

[60] Klenow, Peter. 2003. "Measuring Consumption Growth: The Impact of New and Better Products." Federal Reserve Bank of Minneapolis Quarterly Review, Winter 10-23.

[61] Kocherlakota, N. 1996. "The equity premium: Its still a puzzle." Journal of Economic Literature, 34: 4276.

[62] Krugman, P. 1979. "Increasing returns, monopolistic competition, and international trade." Journal of International Economics. 9 (1979), pp. 469479

[63] Krugman P. 1991. "Increasing Returns and Economic Geography." Journal of Political Economy, 99 (3), p.483-99.

[64] Laibson, D. 1997. "Golden eggs and hyperbolic discounting." Quarterly Journal of Economics, 112: 2 pp 443-77. 
[65] Lancaster, K. 1979. Variety, Equity and Efficiency. New York: Columbia University Press.

[66] LeRoy, S. F., and R. D. Porter. 1981. "The present-value relation: Tests based on implied variance bounds.” Econometrica 49: 555-574.

[67] Lettau, M., and S. C. Ludvigson. 2001. “Consumption, Aggregate Wealth, and Expected Stock Returns.” Journal of Finance, 53: 815 - 850.

[68] 2001. "Resurrecting the (C)CAPM: A Cross-Sectional Test when Risk Premia are TimeVarying.” Journal of Political Economy, 109: 1238 - 1287.

[69] Lucas, R. E., Jr. 1978. “Asset prices in an exchange economy.” Econometrica 46: 1429-1445.

[70] Mankiw, N G, Rotemberg, J., and Summers, L. 1985. “Intertemporal Substitution in Macroeconomics.” The Quarterly Journal of Economics, 100:1, pp 225-51.

[71] McGratten, E., and E. Prescott. 2001. “Taxes, Regulations, and Asset Prices.” NBER Working Paper 8623.

[72] Mehra, R., and E. C. Prescott. 1985. “The equity premium: A puzzle.” Journal of Monetary Economics 15: $145-161$.

[73] Mehra, R., and E. C. Prescott. 2008. “The equity premium: ABCs.” In R. Mehra, ed., Handbook of the Equity Risk Premium. Elsevier, Amsterdam.

[74] Merton, R. C. 1973. “An intertemporal capital asset pricing model.” Econometrica 41: 867-887.

[75] Midrigan, Virgiliu. 2007. Comment. NBER Macroeconomics Annual 2007.

[76] Molinari, B. and Turino, F. 2006. "The role of Advertising in the Aggregate Economy: the Work and Spend Cycle." Mimeo, Universitat Pompea Fabra.

[77] Nevo, A. (2001) "Measuring Market Power in the Ready-to-Eat Cereal Market.” Econometrica 63, 841-890.

[78] Nordhaus, William. 1997. "Do Real Output and Real Wage Measures Capture Reality? The History of Lighting Suggests Not.” In Timothy Bresnahan and Robert Gordon, eds., The Economics of New Goods (Chicago: University of Chicago Press), pp. 29-70.

[79] Normandin, M. and St-Amour P. “Substitution, Risk Aversion, Taste Shocks and Equity Premia.” Journal of Applied Econometrics, 13:3, 265-281.

[80] Piazzesi, M., M. Schneider, and S. Tuzel. 2007. "Housing, Consumption and Asset prices.” Journal of Financial Economics, 83: 531-569.

[81] Pakos, M. 2004. "Asset pricing with durable goods and non-homothetic preferences.” Manuscript, University of Chicago.

[82] Perloff Jeffrey M. 2003. Microeconomics. Third Edition. Addison Wesley Longman.

[83] Rotemberg, J., and M. Woodford. 1995. "Dynamic general equilibrium models with imperfectly competitive product markets”. In T. Cooley (ed.), Frontiers of Business Cycle Research, pp. 243-294. Princeton, NJ: Princeton University Press.

[84] Shiller, R. J. 1981. "Do Stock Prices Move Too Much To Be Justified By Subsequent Changes in Dividends?" American Economic Review, 71: 421-436.

[85] Shleifer, A. 1986. “Implementation Cycles.” Journal of Political Economy. 94:6, pp 1163-90.

[86] Schumpeter J. 1939. Business Cycles: A Theoretical Historical and Statistical Analysis of the Capitalist Process. New York: McGraw-Hill. 
[87] Siegel, J. 1992. "The Equity Premium: Stock and Bond Returns Since 1802.” Financial Analysts Journal. 19:2.

[88] Smookler, J. 1966. Invention and Economic Growth. Cambridge: Harvard University Press.

[89] Steinssen, J., and E. Nakamura. 2006. "Five Facts About Prices: A Reevaluation of Menu Cost Models." Mimeo, Department of Economics, Columbia University.

[90] Stigler G. 1961. “The Economics of Information.” Journal of Political Economy, Vol. 69, No. 3 (June 1961), pp. $213-25$.

[91] Tellis, Gerard J. 1988. "The Price Elasticity of Selective Demand: A Meta-Analysis of Econometric Models of Sales.” Journal of Marketing Research, 25 (November), 331-41.

[92] Weil, P. 1989. “The Equity Premium Puzzle and the Risk-free Rate Puzzle.” Journal of Monetary Economics 24: 401-421.

[93] Yogo, M. 2006. "A Consumption Based Explanation of Expected Stock Returns." Journal of Finance, 61: 539-580.

[94] Yorukoglu, M. 2000. "Product vs. Process Innovations and Economic Fluctuations." Carnegie-Rochester Conference Series on Public Policy, 52:137-163. 